\title{
A local-level, multiple criteria decision aid for climate protection
}

\author{
Lioba Markl-Hummel · Jutta Geldermann
}

Received: 11 September 2012/ Accepted: 7 May 2013/Published online: 9 July 2013

(C) Springer-Verlag Berlin Heidelberg and EURO - The Association of European Operational Research Societies 2013

\begin{abstract}
Climate change is one of the global challenges of the twenty-first century. On international, European and national level, climate protection measures are discussed and reduction targets for greenhouse gas emissions are defined. The local level has a decisive role for putting these targets into practice. Local authorities can be considered as key actors for climate protection as they are the closest political body to citizens. They have a large scope of action including, for example, improved energy efficiency and the use of renewable energies. For the implementation of climate protection, different complex decisions have to be taken considering financial, ecological, political and social criteria. For decision aiding in this context, outranking methods emerge well suited because the decision-makers in politics and administration face incomplete information and they have to choose between alternatives that are not always directly comparable and where no dominating solution that fulfils best all criteria can be identified. A survey among 1,100 municipalities in a German Land allowed evaluating the current status of climate protection on the local level and quantifying the importance of different decision criteria. The article characterises four "moments of decision" during the preparation and implementation of climate protection strategies. It presents a standardised procedure to accompany decision-makers in this context and a generalised criteria tree. These are applied in a case study using the outranking method PROMETHEE for the choice of the retrofitting concept for a primary school.
\end{abstract}

\footnotetext{
L. Markl-Hummel ( $\bowtie)$

Laboratoire Image Ville Environnement UMR 7362 CNRS/UdS, Faculté de Géographie et Aménagement, 3, rue de l'Argonne, 67000 Strasbourg, France

e-mail: marklhummel@gmail.com

J. Geldermann

Chair of Production and Logistics, Georg August Universität Göttingen (D),

Platz der Göttinger Sieben 3, 37073 Göttingen, Germany

e-mail: produktion@wiwi.uni-goettingen.de
} 
Keywords Multiple criteria decision aid - PROMETHEE - Climate protection Energy $\cdot$ Local authorities $\cdot$ Criteria

Mathematics Subject Classification $62 \mathrm{C} \cdot 90 \mathrm{~B} 50 \cdot 91 \mathrm{~B} 06$

\section{Introduction}

The influence of human activities on climate is widely recognised in the scientific community and in society. The Intergovernmental Panel on Climate Change (IPCC 2007) published the resulting environmental and social impacts that can be expected all over the world due to global warming. Consequently, awareness is generally increasing, and at different political levels, solutions are being discussed to mitigate climate change and to reduce energy consumption. On international level, the Kyoto protocol in 1997 and the following UN climate conferences aimed at reducing greenhouse gas (GHG) emissions at a global scale. For Europe, the European Council published in March 2007 its resolution to reduce GHG emissions by $20 \%$ (compared to 1990) until 2020, to increase energy efficiency by $20 \%$ and to reach $20 \%$ of renewable energy by 2020 and Germany aims at reducing GHG emissions by $40 \%$ until 2020 (BMU-Federal Ministry for the Environment 2010). In order to reach these goals, actors on all political and societal levels have to take an active part in climate protection, down to local level. Local authorities play a key role since they are directly affected by climate change and have a broad range of possible actions for its mitigation and adaptation to its consequences. In the frame of the implementation of climate protection (and adaptation) strategies, they face complex decision situations. In Germany, local climate protection activities are mainly of voluntary nature and the financial situation is restricting the freedom of action of local authorities. In fact, climate protection beyond the minimum requirements set by national laws is only an additional task to the numerous duties and commitments local authorities already have. Furthermore, incomplete information, rigid structures and complicated legal and fiscal frame conditions create additional barriers (Markl-Hummel et al. 2010). In decisions, partly conflicting financial, ecological, political and social interests have to be conciliated. Consequently, Multicriteria Decision Analysis (MCDA) methods seem of precious aid to overcome some of these barriers. By now, only few cases of application of MCDA methods on local climate protection strategies can be found in literature. More work has been published dealing with decisions on climate protection on national scale (e.g. Grafakos et al. 2009; Konidari and Mavrakis 2006). They are comparing national political instruments for climate protection. For an example of application of multicriteria decision analysis (MCDA) methods on the issue of adaptation to climate change, cf. Ceccato et al. (2009). Simultaneously, in the field of local energy planning, a growing number of case studies has been carried out (for an overview cf. Oberschmidt 2010; Wang et al. 2009; Diakoulaki et al. 2005; Pohekar and Ramachandran 2004; Greening and Bernow 2004) which can be partly assigned to climate protection (e.g. Bombenger and Waaub 2010; Neves and Leal 2010; Neves et al. 2008; Dinca et al. 2007; Oberti 2004). Nevertheless, they do not 
cover the whole range of decision problems during the preparation and implementation of a climate protection strategy. For that reason, in the present article, some elements of response to the question "How decision aid for climate protection strategies of local authorities can be improved?" are introduced. In the frame of the work at the European Institute for Energy Research (EIFER) and the writing of a thesis (Markl-Hummel 2012), different local authorities have been accompanied during the preparation of their climate protection strategies, and a quantitative survey has been carried out among all 1,100 municipalities in Baden-Württemberg (a German Land) in 2009/2010 (cf. Markl-Hummel et al. 2010, response rate $n=201$ ) aiming at evaluating the current status of climate protection at local level. These projects allow the aggregation of the practical experience in a schematic way. First, the different "moments of decision" that occur during the preparation and implementation of a local climate protection strategy are identified. Second, a standardised procedure to help decision-makers to find the best compromise is presented. The approach is applying MCDA methods highlighting the complete process of decision-making and is based on the assumptions that the decision-maker does not possess exact, complete information without contradictions and cannot always build unequivocal rankings of the alternatives (cf. Roy 1985; Roy and Bouyssou 1993). For these reasons, outranking methods seem well suited and PROMETHEE (Preference Ranking Organisation METHod for Enrichment Evaluations, cf. Brans et al. 1986; Brans and Mareschal 2005) is retained for an illustration of the procedure in a case study. Criteria are assessed by the abovementioned quantitative survey in Baden-Württemberg (cf. Markl-Hummel et al. 2010; Markl-Hummel 2012). Its results can be summarised in a general criteria tree that is then to be adapted for individual cases.

\section{Climate protection in German local authorities}

Local authorities have many possibilities of action for climate change mitigation. Typically, four different roles are outlined, e.g. by the Climate Alliance, the IFEU or the Wuppertal institute: (1) consumer and model, (2) planner and regulator, (3) advisor and promoter, (4) provider and supplier. As "consumer and model", a local administration makes itself an example for the citizens, e.g. by saving resources and by applying a sustainable procurement policy. It can influence energy demand directly through the management of its own energy use, but also indirectly by informing end-users about energy efficient behaviour. As "planner and regulator", it can specify standards and influence urban development, e.g. high urban density or integrated land use and transport planning, and regulate by law the use of renewable energies (e.g. Solarsatzung Marburg 2010 (2010), solar code) or the connection to a local heating grid. As "advisor and promoter", the local authority acts as enabler, sensitizing and informing citizens and provides incentives such as subsidies. As "provider and supplier", it can influence the way the offer is composed. Decisions on the energy mix in favour of more efficient systems and a higher share of renewable energy can also promote local energy production and reduce dependencies on fossil energy resources from other regions. Bulkeley and Kern (Bulkeley and 
Kern 2004) observed that German local authorities have the tendency to primarily occupy an enabling role. Overall, many individual strategies and initiatives with a broad range of different solutions for climate protection can be found in German municipalities. Impulses are mainly bottom-up and no concept is identical to another. One advantage is that strategies and measures tend to be designed for specific local contexts and emanate from them. A disadvantage is that even the balancing methods for $\mathrm{CO}_{2}$ inventories differ a lot in Germany which renders comparison very complicated. The formalisation of the different efforts in a climate protection concept still lacks in many municipalities (cf. Markl-Hummel et al. 2010; Weimer-Jehle et al. 2001). And despite the already achieved savings, a large potential for further emission reduction can still be observed. Main barriers are of financial nature or emerge from a lack of consciousness (Markl-Hummel 2012). A standardised support process could contribute to decreasing costs and raising awareness of different local actors. For that purpose, decisions during the preparation and implementation of a local climate protection strategy are further examined in the following.

Different decisions during the preparation and implementation of a local climate protection strategy

One entry point for the analysis of decisions in local climate protection strategies is the representation of the different stages during their preparation and implementation. Four main stages and "moments of decision" can be identified (cf. Fig. 1). Each one can be characterised by its specific context, its framework, its challenges, the concerned stakeholders and appropriate methods to support the decision (cf. Markl-Hummel 2012).

Strategical decision: definition of objectives, the focus and the strategical orientation for climate protection in the municipality, declaration of intentions

This step results in a political declaration of willingness. For that purpose, the mayor or the person who is the "carrier" of this engagement needs information provided by administration and external partners, e.g. engineering offices or research institutes. This includes an analysis of the current situation of the municipality; a carbon balance and a rough estimation of the potential reductions that can be achieved by climate protection measures (cf. Neves and Leal 2010). The decisionmakers (at this stage, mainly political decision-makers who rely on information collected by the administration) declare their motivation and ambitions and define the general objectives. This can imply the definition of the main axes for the municipality (e.g. "bioenergy") or the quantification of objectives (e.g. "50\% reduction of the current $\mathrm{CO}_{2}$-emissions" or "reaching a share of $50 \%$ of renewable electricity"). At this stage, possible orientations are defined. The system boundaries are determined and ideally, persons in charge of the climate protection strategy and their competences should already be designated to ensure continuity and compliance with the defined goals. 


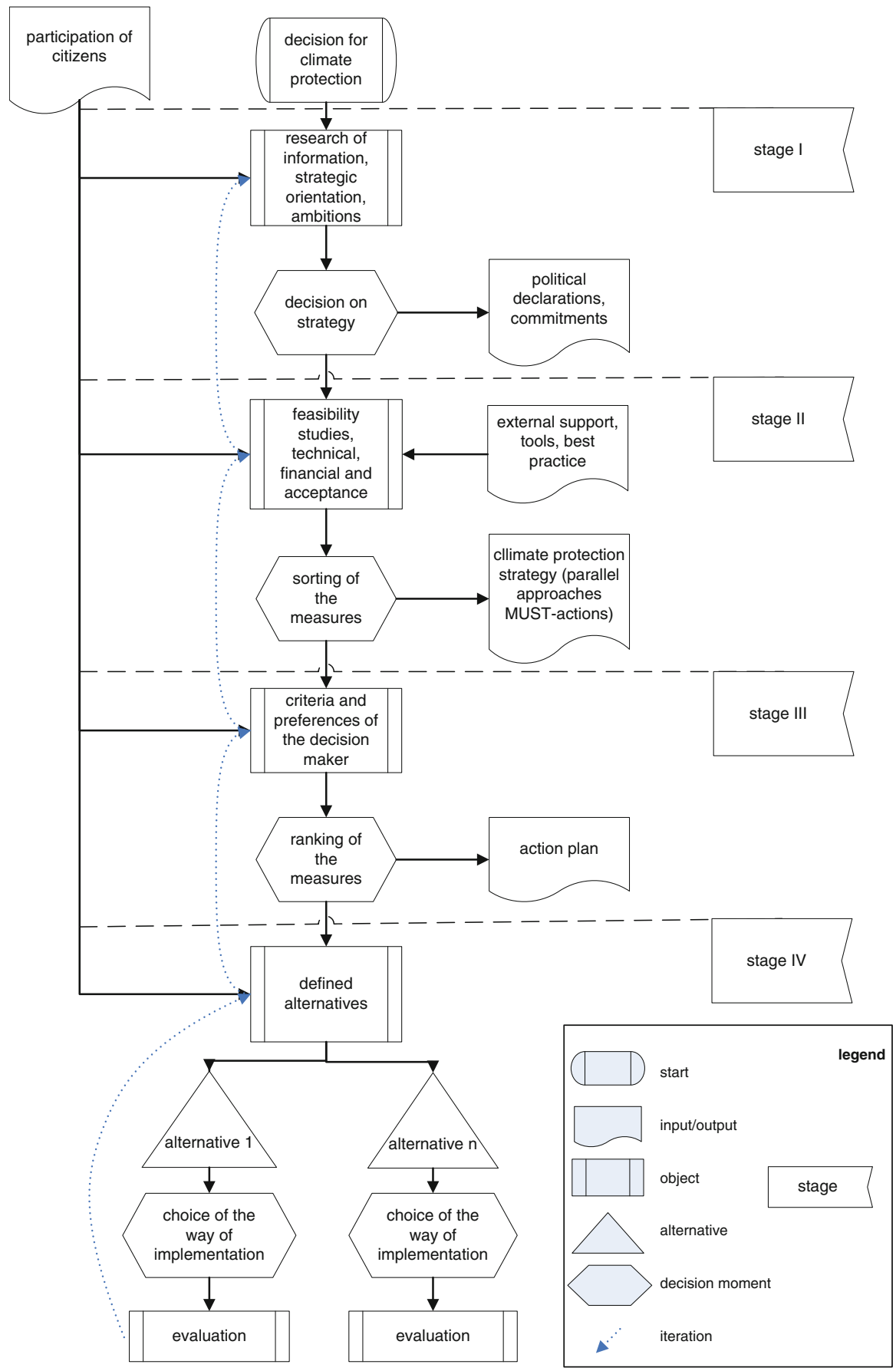

Fig. 1 Decision moments in climate protection in municipalities 
Preparation and conception: assessment of possible actions for the municipality, decision on integration of actions in the climate protection strategy

Once, the political will is assured and pronounced, further analysis of possible actions has to be carried out. To get first ideas, best practice examples of other municipalities can be studied. They are published by associations such as the Climate Alliance or by public bodies. Collected on European level, they provide information on the orders of magnitude of costs and performances of potential measures. Subsequently, the resulting long list of potential actions has to be adapted for the individual case by decision-makers in administration who can be assisted by external experts, representatives of industry, citizens and other stakeholders (e.g. in the form of a working group). For this, preliminary feasibility studies might be carried out. When feasible actions have been identified and described for the local context, a sorting problem ( $\beta$ type of decision, referring to Roy 1985) has to be resolved to decide whether the actions are retained or not for the climate protection strategy. Choices are made according to the adaptability and the compatibility of the actions with the strategy. Actions that have already been scheduled before can also be integrated in the climate protection strategy. In practice, the methods applied by local authorities to carry out the sorting vary considerably (Neves and Leal 2010). The resulting concept will be voted by the council to assure its bindingness. A typical element of the resulting shortlist could be for example the "energetic refurbishment of schools".

Action planning: definition of the action plan (ranking of pre-identified actions according to decision-makers preferences, scheduling)

When the climate protection strategy has been voted, setting the general framework, it has to be transformed into a concrete schedule with a higher degree of details. It is elaborated when which action will be carried out by whom. This requires project management techniques and investment programme planning complemented by methods of Multicriteria Decision Aiding. Administration and sub-contractors are involved. One prerequisite is the exact evaluation of the chosen actions (impacts, budget, delays, involved actors, conflicts and synergies between actions) and the elicitation of preferences of the decision-makers (e.g. mayor, council) and stakeholders (citizens, local economy, action groups). This allows at least some comparisons between available alternatives and, in a second step with the help of outranking methods, building a partial or complete ranking of the alternatives (type of decision $\gamma$ ). At this stage, Portfolio Decision Analysis can also be applied for defining a subset of alternatives out of a large panel of possible actions. But in practice, information is often not completely formalised and available for computation. The main difficulty lies in comparing actions which belong to different cost centres, areas of responsibility and time frames. The resulting action plan may contain for example the action "energetic refurbishment of the primary school in the city centre in 2012 respecting the budget of $50,000 €$ '. 
Realisation: for the implementation of an action, choice between different alternative variants

Finally, with each action that has to be carried out, different alternatives for their practical implementation occur (e.g. different materials, technologies, etc.). These are identified and described according to the criteria that measure their performance. There is not always one optimal solution; the objectives are met more or less by the different alternatives. On an operational level, the decision-maker is the responsible person in administration. She should take into account the preferences of the different stakeholders. These have to be assessed in order to render the decision process as transparent as possible and to improve the acceptance of the result. At the end, one action is chosen (problem of choice, $\alpha$ ) and the action is planned in detail. A corresponding example would be "primary school in the city centre: replacement of the old heating by a pellet heating, insulation of the walls, replacement of the windows". Between these four "decision moments", there are of course feed-back loops and the process can be considered as an iterative circle which is not always following chronological order. The definition of objectives and the continuous monitoring and controlling of the actions are to be considered as important success factors for local climate protection (Laborgne and Huber 2008). Another success factor is the integration of citizens. This can be accomplished at all stages and communication and public relations play an important role throughout the entire process.

The scheme can be applied to different countries, especially those where explicit climate protection strategies are defined by local authorities, such as in France where all municipalities with more than 50,000 inhabitants are obliged to define a climate protection strategy (Plan Climat Energie Territorial, PCET). In Germany, the observed approaches are more heterogeneous. Often, there is no general strategy. There are financial incentives for the definition of climate protection strategies but in practice, only few municipalities already adopted one. In the initially mentioned online survey carried out in Baden-Württemberg (cf. MarklHummel et al. 2010; Markl-Hummel 2012), only $17.9 \%$ of all respondents affirmed the question "Do you have a climate protection concept in your municipality?". Nevertheless, the identified decision moments can, at least partly, also be found in a municipality if no overall strategy has been defined. And at all stages, not only in the initial phase, there is need for decision aiding.

\section{Standardized procedure}

The analysis of the different stages of the preparation and implementation of a climate protection strategy reveals that the persons in charge (from administration and politics) can be supported by different means. On the one hand, information can be provided (e.g. data bases, best practices) and management tools can help to structure the process and to integrate evaluation loops. On the other hand, there is also a need for a standardised procedure of decision aiding in order to help the political decision-makers to find the best compromise and to render the decision process more transparent (e.g. for communication). The integration of the different 
stakeholders and the interaction between the analyst and the decision-makers can be facilitated. Oberti (2004, p. 6) developed a participative approach that has been modified and adapted for the present work (cf. Fig. 2). It aims at structuring the decision procedure and rendering it transparent. The whole process is of importance. The implementation is not obligatorily carried out in a linear order from I to X. Especially, the phases III and IV can also be inverted (cf. Keeney 1992; Gregory et al. 2001) in order to leave more flexibility for the creation of innovative alternatives. This will depend on the degree of freedom that is possible in the decision-aiding process and on the focus that is set by the analyst according to the demand of the decision-makers. Anyway, the content of the single phases can be redefined, even if the process is already advanced (iterative feedback loops). This scheme has been tested on a case study (cf. "Phase I: clarification of the situation and of the problem").

Criteria for the choice of climate protection actions

Decisions on climate protection issues have to conciliate different objectives: for example, environmental targets are partly in conflict with political strategies to satisfy the electors priorities and the financial viability of the actions for climate protection. The different criteria of choice are of financial (like initial investment, return on investment, etc.), ecological (like reduction of $\mathrm{CO}_{2}$ emissions, primary energy use, etc.), political (legitimacy, interests of the parties, etc.) and social nature (acceptance, jobs, etc.). In most cases, no dominating solution can be determined that fulfils best all criteria.

In order to get a detailed overview, an empirical approach has been applied. One part of the survey among all municipalities in Baden-Württemberg mentioned before (cf. Markl-Hummel et al. 2010; Markl-Hummel 2012) was dedicated to the criteria and preferences that determine the decisions for one action or another. "Which criteria were decisive for the thematic focus of your actions against climate change?" The questionnaire proposed 18 different criteria (identified in literature, e.g. Oberti 2004; Bombenger and Waaub 2010; Fischer and Kallen 1997; Hennicke et al. 1997; Prose et al. 1993; Grafakos and Zevgolis 2008). The surveyed persons (members of administration) were asked to grade the importance of each criterion on a scale from 0 to 10,0 being the less important. The proposed criteria ranged from financial to ecological and from the short-term or long-term character of the evaluated action to the effort for implementation. Another category of criteria concerned the local context, like the availability of resources as well as the local creation of jobs or the acceptance by the citizens. The option that allowed describing additional criteria has not been used by the respondents. It should be noted that the proposed criteria were not independent. For instance, the proposition of different financial terms which are rather close aimed at finding out which concept is most relevant for decision-makers concerning the financial viability of an alternative. That also holds for the criteria $\mathrm{CO}_{2}$ savings and the environmental protection, which are not independent of each other. However, the decision-makers reckoned all aspects individually as decision relevant and could not agree on more aggregated criteria. 


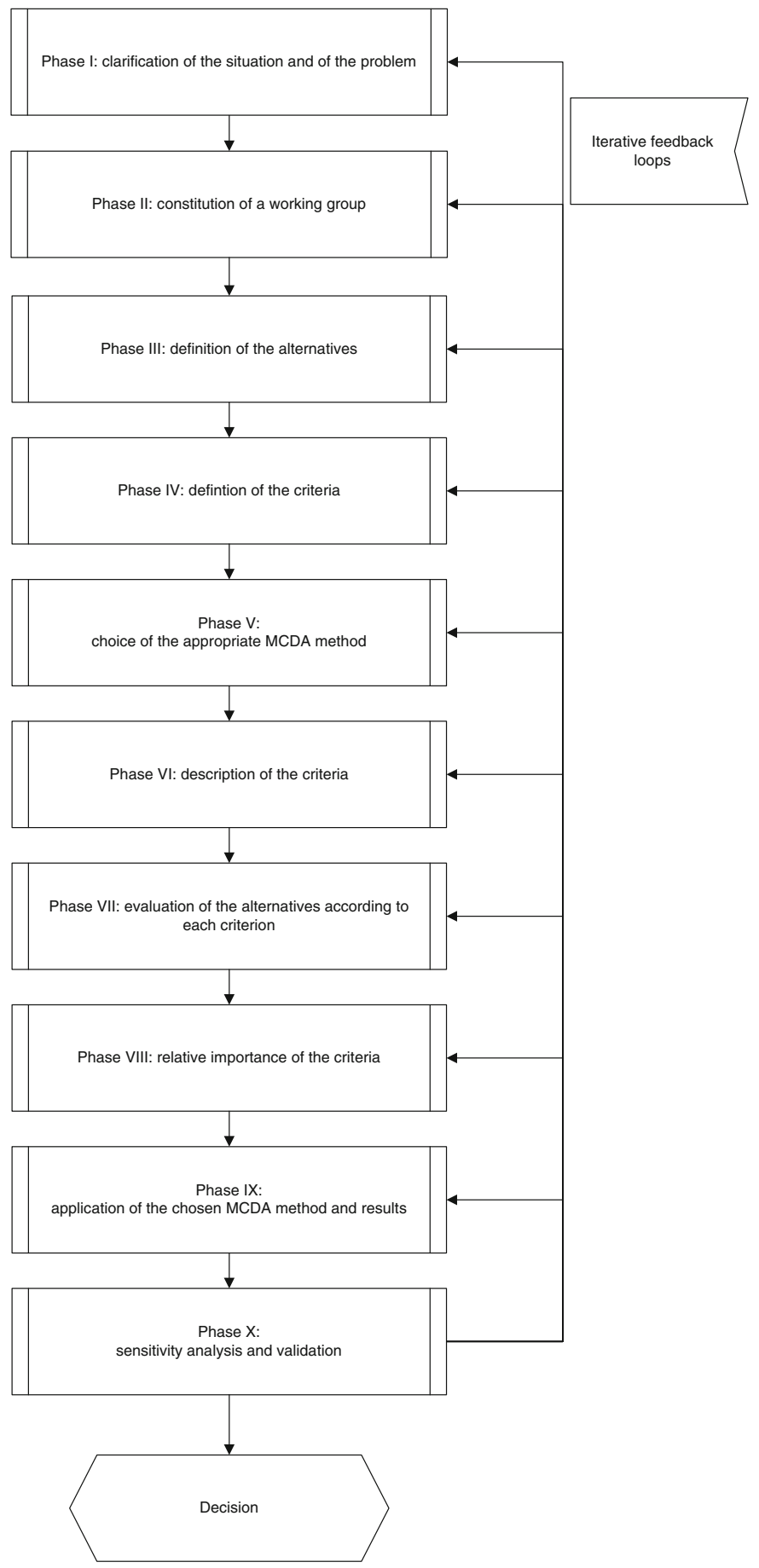

Fig. 2 Phases of the decision-aiding process 


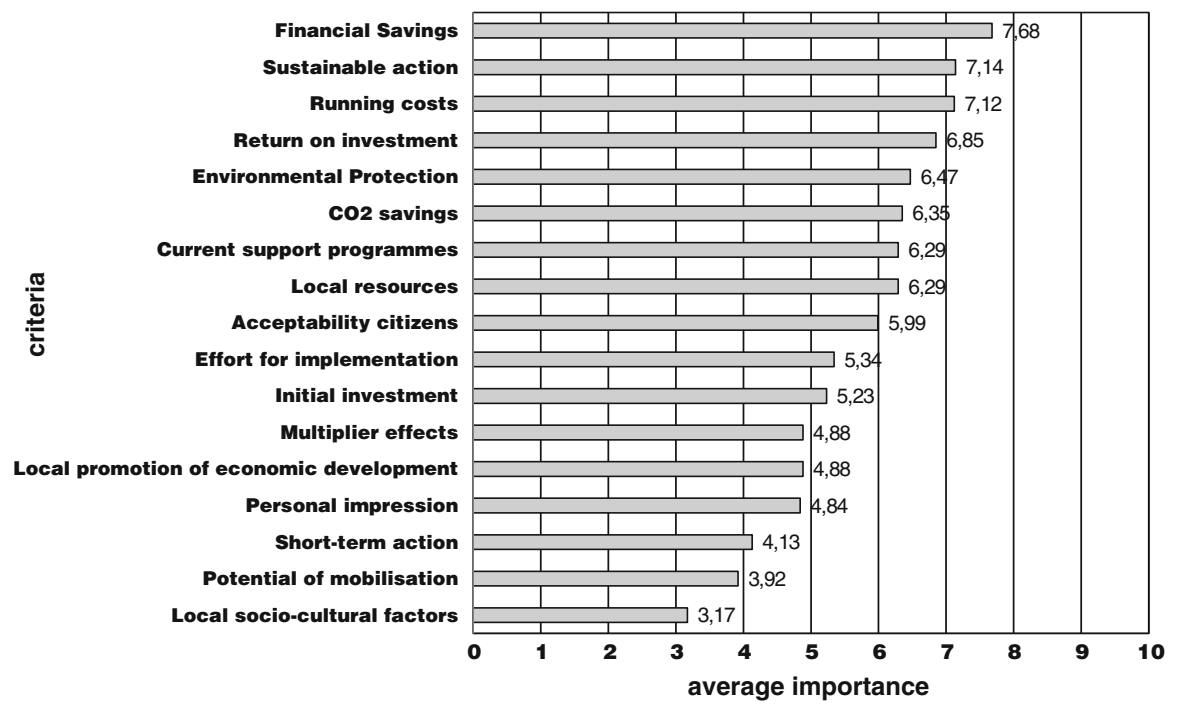

Fig. 3 Average values for the importance of the criteria (scale 1-10)

Figure 3 represents the average value for every criterion and Table 1 the detailed rating of each criterion. The highest ranked criteria were mainly of financial nature, namely "financial savings" (7.68 as average value) or "running costs" (7.12). Second, environmental criteria like "sustainability" (7.14), "environmental protection" (6.47) or " $\mathrm{CO}_{2}$ savings" (6.35) were highlighted. "Acceptance of the actions by the citizens" (5.99) or "current support programmes" (6.29) were rated with rather average values. The less importance was assigned to socio-cultural reasons, the "potential of mobilisation (3.92) and "local socio-cultural factors (3.17).

By the means of a factor analysis (cf. Rencher 2002, p. 408), the different criteria have been grouped. Four clusters could be identified (cf. Fig. 4) containing all criteria except for the criterion "availability of local resources" (its commonality was beyond 0.4). Each cluster can be assigned to one dimension or general objective. The criteria "initial investment", "financial savings", "running costs" and "return on investment" correlate. They are financially motivated criteria. The criteria "acceptability citizens", "potential of mobilisation", "effort for implementation", "short-term action", "local promotion of economic development" and "local socio-cultural factors" refer to the importance of the local context, especially of the citizens. The criteria " $\mathrm{CO}_{2}$ savings", "sustainable actions" and "environmental protection" can be summarised as the ecological dimension. The two criteria "current support programmes" and "personal impression" also correlate. They are summarised in one category named "inner and outer drivers". In one case, the "inner drivers" dominate, i.e. the decision-makers decide according to their very subjective personal value system. In the other case, they are influenced by external opportunities (e.g. support programmes). The appraisal of the criteria does not correlate with the size of the community. Nonetheless, the range of judgements varies considerably from one criterion to another. For instance, the criterion 
Table 1 Importance of criteria for the choice of the measures for local climate protection

\begin{tabular}{|c|c|c|c|c|c|c|c|c|c|c|c|c|c|}
\hline Criteria & $\begin{array}{l}0 \\
(\%)\end{array}$ & $\begin{array}{l}1 \\
(\%)\end{array}$ & $\begin{array}{l}2 \\
(\%)\end{array}$ & $\begin{array}{l}3 \\
(\%)\end{array}$ & $\begin{array}{l}4 \\
(\%)\end{array}$ & $\begin{array}{l}5 \\
(\%)\end{array}$ & $\begin{array}{l}6 \\
(\%)\end{array}$ & $\begin{array}{l}7 \\
(\%)\end{array}$ & $\begin{array}{l}8 \\
(\%)\end{array}$ & $\begin{array}{l}9 \\
(\%)\end{array}$ & $\begin{array}{l}10 \\
(\%)\end{array}$ & $\begin{array}{l}\text { Mean } \\
\text { (abs.) }\end{array}$ & $\begin{array}{l}\text { All } \\
(n)\end{array}$ \\
\hline Initial investment & 12.3 & 2.2 & 8.9 & 4.5 & 6.7 & 16.2 & 12.8 & 8.4 & 14.5 & 4.5 & 8.9 & 5.24 & 179 \\
\hline Financial savings & 0.0 & 0.5 & 0.5 & 1.1 & 2.7 & 12.6 & 8.2 & 13.2 & 28.0 & 7.1 & 25.8 & 7.68 & 182 \\
\hline Running costs & 3.3 & 1.1 & 2.8 & 3.3 & 1.7 & 11.7 & 7.2 & 11.1 & 31.7 & 5.6 & 20.6 & 7.12 & 180 \\
\hline $\begin{array}{l}\text { Return on } \\
\text { investment }\end{array}$ & 2.2 & 1.1 & 0.0 & 4.9 & 4.9 & 20.8 & 8.7 & 8.2 & 23.0 & 9.8 & 16.4 & 6.85 & 183 \\
\hline $\begin{array}{l}\text { Acceptability } \\
\text { citizens }\end{array}$ & 2.8 & 0.0 & 6.2 & 6.7 & 5.1 & 24.7 & 10.7 & 10.7 & 22.5 & 2.8 & 7.9 & 5.99 & 178 \\
\hline $\begin{array}{l}\text { Effort for } \\
\text { implementation }\end{array}$ & 8.7 & 0.6 & 7.5 & 4.0 & 8.1 & 23.1 & 13.3 & 12.7 & 15.0 & 0.6 & 6.4 & 5.34 & 173 \\
\hline Short-term action & 12.0 & 4.0 & 20.0 & 6.3 & 9.1 & 22.3 & 4.6 & 7.4 & 9.7 & 0.6 & 4.0 & 4.11 & 175 \\
\hline $\begin{array}{l}\text { Local promotion } \\
\text { of economic } \\
\text { development }\end{array}$ & 15.3 & 1.7 & 8.5 & 5.7 & 9.1 & 18.8 & 7.4 & 9.7 & 13.1 & 2.3 & 8.5 & 4.88 & 176 \\
\hline $\begin{array}{l}\text { Potential of } \\
\text { mobilisation }\end{array}$ & 21.7 & 1.8 & 11.4 & 5.4 & 7.2 & 27.7 & 6.0 & 5.4 & 10.8 & 1.2 & 1.2 & 3.92 & 166 \\
\hline Multiplier effects & 12.2 & 5.8 & 5.8 & 5.8 & 8.1 & 25.0 & 6.4 & 6.4 & 14.0 & 3.5 & 7.0 & 4.88 & 172 \\
\hline $\begin{array}{l}\text { Local socio- } \\
\text { cultural factors }\end{array}$ & 36.8 & 2.3 & 14.9 & 2.3 & 4.6 & 18.4 & 2.3 & 6.9 & 4.0 & 1.1 & 6.3 & 3.17 & 174 \\
\hline $\mathrm{CO}_{2}$ savings & 4.8 & 0.5 & 1.6 & 8.1 & 8.1 & 17.2 & 8.6 & 11.8 & 17.2 & 3.8 & 18.3 & 6.36 & 186 \\
\hline Sustainable action & 2.7 & 0.5 & 2.7 & 2.7 & 1.6 & 17.6 & 7.1 & 9.9 & 25.3 & 5.5 & 24.2 & 7.14 & 182 \\
\hline $\begin{array}{l}\text { Environmental } \\
\text { protection }\end{array}$ & 4.0 & 1.7 & 4.5 & 2.8 & 2.8 & 21.5 & 6.2 & 16.9 & 18.6 & 4.5 & 16.4 & 6.47 & 177 \\
\hline $\begin{array}{l}\text { Current support } \\
\text { programmes }\end{array}$ & 4.6 & 0.6 & 7.4 & 2.9 & 4.0 & 21.1 & 9.1 & 10.3 & 17.7 & 8.0 & 14.3 & 6.28 & 175 \\
\hline $\begin{array}{l}\text { Personal } \\
\text { impression }\end{array}$ & 10.4 & 3.1 & 10.4 & 6.7 & 5.5 & 22.7 & 9.8 & 13.5 & 13.5 & 0.0 & 4.3 & 4.84 & 163 \\
\hline Local resources & 14.9 & 1.7 & 6.6 & 3.9 & 0.0 & 11.0 & 3.3 & 8.8 & 13.8 & 4.4 & 31.5 & 6.29 & 181 \\
\hline
\end{tabular}

Scale $0-10,0=$ not important at all, $10=$ most important, in percent

"availability of local resources for renewable energy" is rated most often with the best value (10/10) in about $31 \%$ of the cases and with $0 / 10$ in $15 \%$. For this criterion, opinions differ a lot and are rather extreme. One reason might be that for those communities with many local resources, this seems an important connecting factor for local climate protection. Anyhow, no significant dependency could be detected between those communities which declared having installed (or planning the installation of) biomass plants in another question of the survey and those who highlighted this decision criterion. Concerning financial criteria, another differentiation has been effected. Long-term measures with savings over their lifetime appear more important than the initial investment. This indicates that climate protection activities are perceived as an opportunity to reduce running costs and greenhouse gas emissions simultaneously. Except for the acceptance of the measures among citizens, social criteria like the potential of mobilisation and 


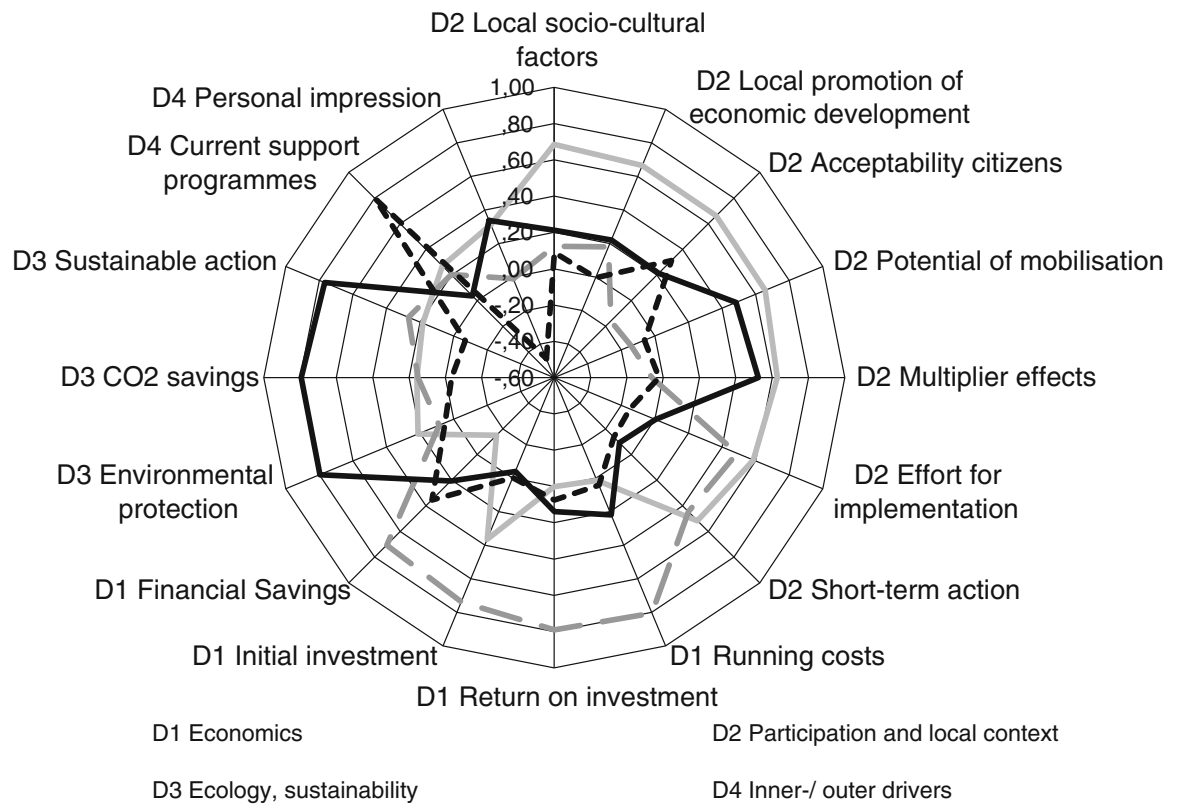

Fig. 4 Rotated components matrix of the decision criteria

multiplication are rated rather low. Climate protection appears as internal duty of the administration and the integration and motivation of the citizens still seems to play a minor role. The results are represented in form of a criteria tree (Fig. 5). Only those criteria rated with at least an average value of five have been taken into account. Moreover, each dimension was represented. The criteria are the measures of performance by which climate protection actions can be evaluated. Nevertheless, this "ideal criteria tree" has to be adapted to every individual case, i.e. criteria have to be defined more precisely for the application together with the decision-makers (concerning the scale, the unit of measurement, etc.). One example is presented in the following case study.

\section{Case study on the choice of the energetic refurbishment concept for a primary school}

The case study on the energetic refurbishment of a primary school in Germany can be assigned to the fourth "moment of decision" during the implementation of a climate protection strategy (cf. Fig. 1), the choice between different alternatives for the realisation of one action. It is structured according to the developed standardised procedure (cf. Fig. 2) and based on a real case. The decision situation can be classified as typical. Each larger municipality possesses public buildings and has to decide regularly how to preserve them or to improve their current performance. Normally, each project competes with other similar projects that should be conducted and that are financed out of the same, limited budget. At the same time, 


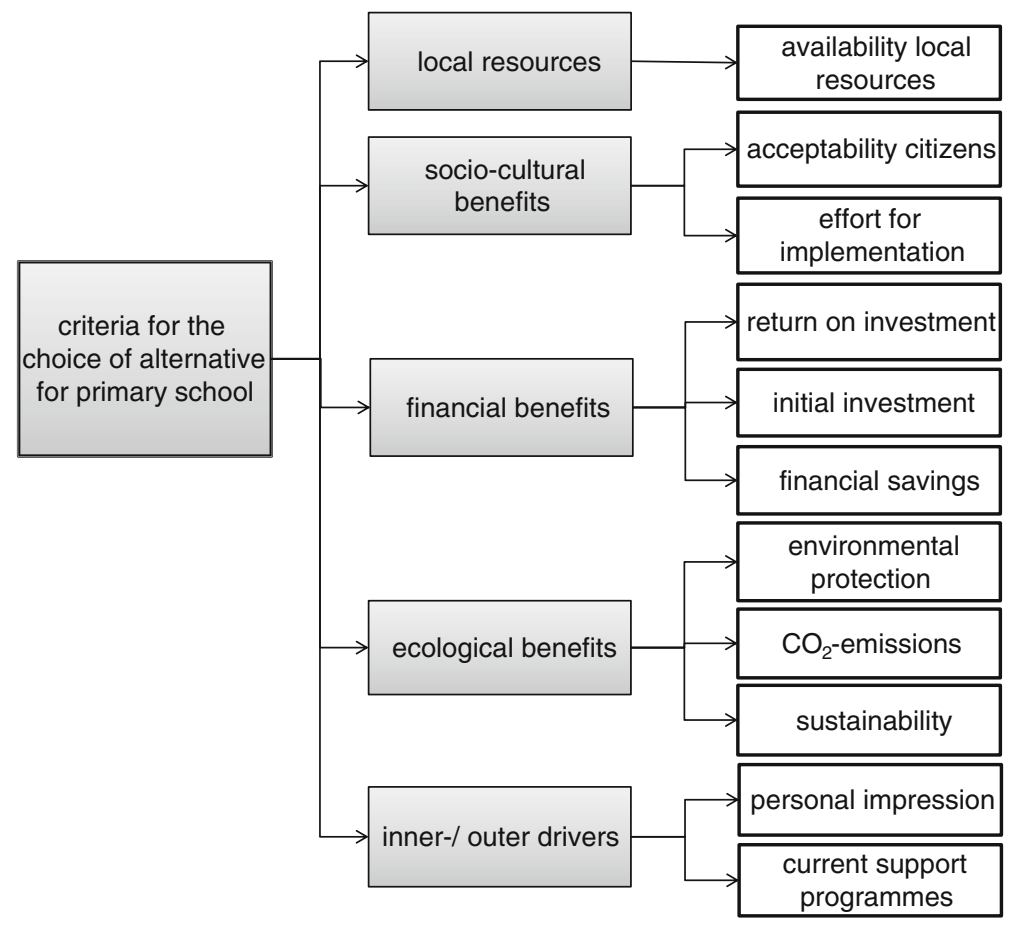

Fig. 5 Criteria tree for local climate protection measures

an improvement of the thermal performance of a building will decrease operational costs and generate savings for the municipality. Moreover, works can be spread over several years and the corresponding annual budgets. The case study aims at illustrating how MCDA methods can help structuring the decision process, concentrating on Multiattribute Decision Making (MADM). In theory, Multiobjective Decision Making (MODM) methods can help finding the optimal technical solution for refurbishment according to different objectives and out of a multitude of possibilities (cf. e.g. Asadi et al. 2012; Diakaki et al. 2010). Portfolio Decision Analysis (PDA, cf. Salo et al. 2011) in general helps defining a subset of alternatives when the number of possible combinations of single measures is very high. Nevertheless, in the present case, a preselection has already been performed by the municipality. The necessary effort for data collection was reduced and it appeared more important that the analyst evaluates the decision situation and proposes appropriate MADM methods for the interaction and the elicitation of preferences of the decision-makers. Typically, in such a decision, more than one decision-maker is involved. They can be integrated into the process by the means of group decision methods (cf. e.g. Weissfloch and Geldermann 2012; Macharis et al. 1998; Behzadian et al. 2011). The presented case study illustrates the broad range of preferences of the different concerned parties in a generalized way in the frame of its sensitivity analysis representing extreme preference profiles as they can be found in other municipalities. 
Phase I: clarification of the situation and of the problem

For the clarification of the situation, the energy manager of the city has been interviewed and the accessible information, including plans and existing pre-studies have been assessed. The concerned building is a primary school in Germany which can be considered as typical. Its initial thermal standard is insufficient and the existing oil boiler has to be exchanged. Different possible solutions exist but no unequivocal preference of the decision-makers for one alternative can be detected. The problem is complex because several single measures shall be combined (heating solution, thermal standard of the building and a solar panel) and interactions between these single measures within one "package" should be reflected. On the one hand, ecological and social criteria are to be taken into account. On the other hand, the municipality has a limited budget. Finally, a compromise should satisfy the decision-makers and the concerned stakeholders.

\section{Phase II: constitution of a working group}

In order to get a balanced decision, it is important to integrate the different concerned stakeholders in the decision process. In the present case, this would ideally consist in the mayor (who takes the final decision), members of administration who are in charge of the school, the energy manager of the city (who knows very well the technical details of the concerned building), an engineering office who calculated different heating solutions and some representatives of the school itself (e.g. the headmaster and a representative of the parents). The janitor of the school should also be involved as he will be the one who will operate and maintain the new heating system. This group would reflect the different interests and the influence of each stakeholder on the decision could be translated into weights. In practice, in the case study, only the energy manager was available for detailed discussions. In a kind of role game, she represented the positions of the other actors and described their influence. In fact, it turned out that the preferences of the mayor were largely dominating the choice. This is typical in small municipalities. In order to present a case which is not biased too much, in phase VII, the weights of the survey have been applied on the criteria. The lack of availability of the other parties was also the reason why no group decision technique was applied.

Phase III: definition of the alternatives

The different alternatives are composed of three basic components:

1. The heating solution:

- the existing oil-fired heating;

- natural gas heating;

- pellet heating;

2. The extension of the thermal renovation of the building and its equipments: 
- no measures;

- renovation "light": insulation of the basement ceiling and the flat roof, new lightning system, sun protection on the south-oriented windows;

- renovation "complete": like "renovation light", additional insulation of the external walls, replacement of the windows, sun protection on all windows.

3. the additional installation of a photovoltaic system to produce "green" electricity.

The single components cannot simply be added up and ranked because there are interactions, e.g. between the renovation level and the dimensioning of the new heating system. In order to get a reference for energy costs and $\mathrm{CO}_{2}$-emissions, the alternative "doing nothing" has been analysed, too. This results in the following 18 combinations (with short name):

1. Doing nothing (keeping the existing oil-fired heating (a1)

2. Installation of a natural gas boiler (a2)

3. Installation of a pellet heating (a3)

4. Thermal renovation "light" (a4)

5. Thermal renovation "complete" (a5)

6. Natural gas boiler and thermal renovation "light" (a6)

7. Natural gas boiler and thermal renovation "complete" (a7)

8. Pellet heating and thermal renovation "light" (a8)

9. Pellet heating and thermal renovation "complete" (a9)

10. Photovoltaic (PV) system (a10)

11. Natural gas boiler and PV system (a11)

12. Pellet heating and PV system (a12)

13. Thermal renovation "light" and PV system (a13)

14. Thermal renovation "complete" and PV system (a14)

15. Natural gas boiler, thermal renovation "light" and PV system (a15)

16. Natural gas boiler, thermal renovation "complete" and PV system (a16)

17. Pellet heating, thermal renovation "light" and PV system (a17)

18. Pellet heating, thermal renovation "complete" and PV system (a18).

Phase IV: determination of criteria for the evaluation

The criteria tree (Fig. 6) has been generated based on the "ideal" criteria tree (Fig. 5) and adapted to the concrete case. The main objectives have been kept. Then, the criteria have been detailed in close exchange with the municipality. In an interview with the energy manager of the city, the profitability, the $\mathrm{CO}_{2}$-emissions, independence and exemplarity have been highlighted. This has been compiled as follows: the "personal impression" is replaced by the criterion "independence", the most important "inner driver", in this way also representing the availability of local resources. "Current support programmes" are the "outer drivers". They are not independent from the financial criteria "initial investment" because subsidies will lower the latter. Anyhow, both criteria are not directly correlated. The socio-cultural context is represented by "exemplarity", i.e. the potential of communication on the 


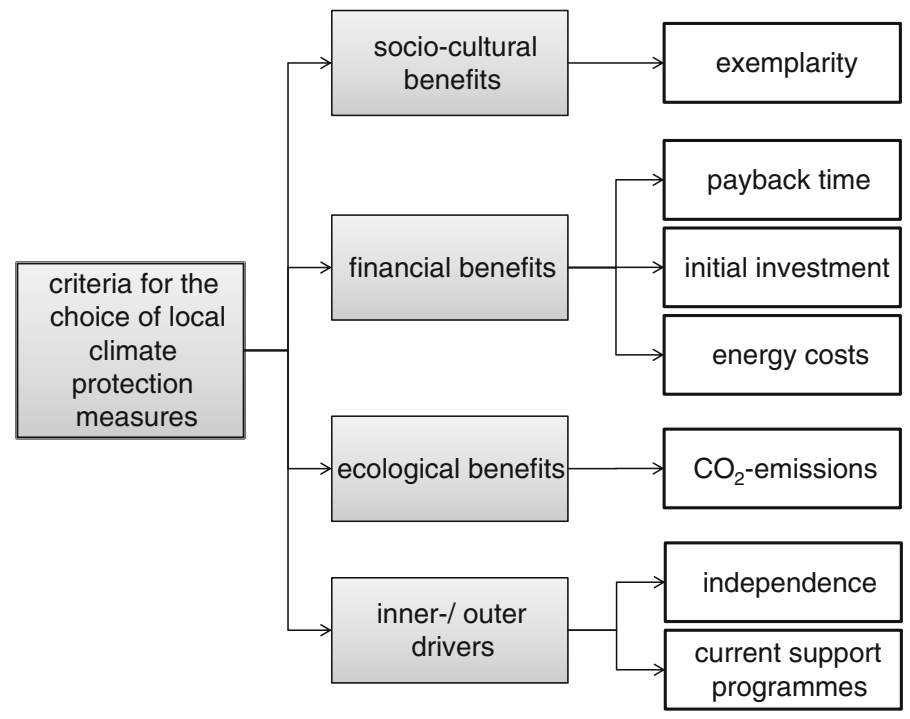

Fig. 6 Criteria tree for the choice of a renovation alternative for a primary school

project. The return on investment is reflected in the (discounted) "payback time" and the "financial savings" in "energy costs". The three financial criteria are not completely independent, but the decision-makers indicated that they all play an important role for the evaluation of the different alternatives. Eventually, the 18 alternatives are analysed according to the criteria represented in Table 2.

The municipality has large constraints concerning the initial investment. "The most important keyword is the refurbishment backlog. The measures are implemented bit by bit. Not all measures can be realised at once." (the energy manager). As a consequence, it cannot be assumed that all possible combinations of measures can really be implemented. But the exact value for the maximum investment could not be defined. Some opportunities also further changed the initial situation. For example, the energy manager explained that "The old room with the oil tank could be transformed into the pellet stock." Consequently, no additional costs were incurred for stocking the wood pellets. For that reason, a final step has been included in the analysis: the best ranked alternative is checked according to its financial feasibility before the final choice.

Phase V: choice of the appropriate MCDA method for the problem to analyse

In the present case, the number of alternatives is limited. The goal is not to find out the optimal technical refurbishment, but to accompany the municipality for finding the best suited compromise of a list of defined alternatives. As qualitative and quantitative criteria are to be taken into account, an outranking method has been chosen to analyse the decision problem (cf. Roy 2005). PROMETHEE (Preference Ranking Organisation METHod for Enrichment Evaluations) has been retained because graduated preference functions and threshold levels can be defined and explained to the decision- 
Table 2 Description of the criteria

\begin{tabular}{|c|c|c|c|c|}
\hline Criterion & $\begin{array}{l}\operatorname{Min} / \\
\max \end{array}$ & Unit & Scales & Objective \\
\hline Exemplarity & Max & $\begin{array}{c}\text { Qualitative, } \\
\text { scale 1-5 }\end{array}$ & $\begin{array}{l}\text { "Standard", "slightly better than } \\
\text { standard", "potential for } \\
\text { communication", } \\
\text { "innovative", "very innovative" }\end{array}$ & Socio-cultural benefits \\
\hline Payback time & Min & Years (a) & - & Financial benefits \\
\hline Initial investment & Min & $€$ & - & Financial benefits \\
\hline Energy costs & Min & $€ /$ year & - & Financial benefits \\
\hline $\mathrm{CO}_{2}$-emissions & Min & $\mathrm{kg} /$ year & - & Ecological benefits \\
\hline Independence & $\operatorname{Max}$ & $\begin{array}{l}\text { Qualitative, } \\
\text { scale 1-5 }\end{array}$ & $\begin{array}{l}\text { "Dependent on oil" (1), } \\
\text { "dependent on gas" } \\
\text { (2), "independent from fossil } \\
\text { fuels"(5) }\end{array}$ & Inner/outer drivers \\
\hline $\begin{array}{c}\text { Current support } \\
\text { programmes }\end{array}$ & $\operatorname{Max}$ & $\begin{array}{c}\text { Qualitative, } \\
\text { scale 1-5 }\end{array}$ & $\begin{array}{l}\text { "No support", "very little support", } \\
\text { "some support", "attractive } \\
\text { support", } \\
\text { "very attractive support } \\
\text { programmes" }\end{array}$ & Inner/outer drivers \\
\hline
\end{tabular}

makers (cf. Brans et al. 1986; Brans and Mareschal 2005; Geldermann 1999). This responds well to the way how decisions are taken in practice. Partial rankings (PROMETHEE I), incomparability and the negative as well as the positive flows are represented in addition to the complete ranking (PROMETHEE II). This fits well with the need for improved transparency that balances the "bounded rationality" and lack of consciousness on their own preferences of the decision makers (cf. Simon 1976). Moreover, the possibilities of visualisation in GAIA PROMETHEE seemed particularly interesting for the discussion of the results (cf. Hayez et al. 2009). Other outranking methods (cf. Figueira et al. 2005) would also have been suitable but the previous experience of the analysts also influenced the choice of the method. Another reason was the availability of different commercial or open source software packages to apply PROMETHEE. In the present work, D-Sight (developed by Decision Sights ${ }^{1}$ ) was used for the calculation and the visualisation of the rankings.

Phase VI: description of the criteria

In the method PROMETHEE, a general preference function reflecting best the decision-makers preferences is assigned to every criterion. In the case study, Gaussian preference functions have been chosen for all quantitative criteria, in order to show that small differences between the values of the criteria only induce small differences in the preference. Moreover, Gaussian preference functions are very

\footnotetext{
${ }^{1}$ Decision Sights is a spin-off company of the Université Libre de Bruxelles developed under a grant from the Walloon Region. D-Sight is the core product of Decision Sights. It is a decision aid software based on the PROMETHEE GAIA methodology (http://www.decision-sights.com, last retrieved on 23.04.2012).
} 


\begin{tabular}{|c|c|c|c|c|c|c|c|c|c|c|}
\hline Criteria & Type & Min/Max & Function & AbsiRel & Indiff, & Pref. & Weight & Unit & Scale & Decimals \\
\hline initial investment & Pair Wise & Minimize & Gaussian & Ábsolute & & 47.000 & $12,6 \%$ & छ & Numerical & 1 \\
\hline energy costs & Pair Wise & Minimize & Gaussian & Absolute & & 5.000 & $17,1 \%$ & Ela & Numerical & 1 \\
\hline payback time & Pair Wise & Minimize & Gaussian & Absolute & & 3 & $16,5 \%$ & a & Numerical & 1 \\
\hline CO2-emissions & Pair Wise & Minimize & Gaussian & Absolute & & 23.000 & $15,3 \%$ & $\mathrm{kgja}$ & Numerical & 1 \\
\hline current support programmes & Pair Wise & Maximize & Level & Relative & 0 & 2 & $15,1 \%$ & & support pro... & 1 \\
\hline independence & Pair Wise & Maximize & Level & Relative & 0 & 2 & $11,6 \%$ & & Independence & 1 \\
\hline exemplarity & Pair Wise & Maximize & Level & Relative & 0 & 2 & $11,7 \%$ & & Exemplarity & 1 \\
\hline
\end{tabular}

Fig. 7 Weighting and preference functions of the criteria (representation with D-Sight)

stable (Brans et al. 1986; Brans and Mareschal 2002). The thresholds for the preference have been calculated according to Tsoutsos et al. (2009): the threshold for indifference $q$ accounts for $5 \%$ of the range of all possible values (cf. evaluation of the alternatives in phase $\mathrm{V}$ ), the threshold for strict preference $p$ amounts to $30 \%$ and $s$ is in the mean between $q$ and $p$. For criteria with qualitative scales, level preference functions have been chosen with $q=0$ and strict preference from $p=2$. The result is shown in Fig. 7. The relative weights are determined in phase VIII.

Phase VII: evaluation of the alternatives according to each criterion

For the technical and economical evaluation of the alternatives, a free online software tool was applied. The Energy Concept Adviser (ECA) is a decision support tool for educational buildings. Prepared under the IEA ECBCS programme Annex 36-'Retrofitting of Educational Buildings' (http://www.annex36.de), it provides energy savings and costs for retrofit technologies/strategies selected to be considered for improving energy efficiency of the analysed building (Erhorn et al. 2002). Five renovation concepts have been developed with the help of the Energy Concept Adviser:

1. Exchange heating system: new natural gas boiler,

2. Thermal renovation "light",

3. Thermal renovation "complete",

4. New natural gas boiler combined with thermal renovation "light",

5. New natural gas boiler combined with thermal renovation "complete".

One advantage of this software is the automatic check on plausibility. For instance, it warned that there could be overheating in summer, if no sun protection was installed on the windows of the south-side. Moreover, the programme takes into account synergy effects between the different single renovation measures and calculates the resulting energy consumption and costs.

In detail, the measures have been defined as follows:

- Heating: Condensing boiler 35/28, installation of mechanical ventilation (with $80 \%$ heat recovery).

- Thermal renovation "light": Insulation of the ground plate $(6 \mathrm{~cm}$ polystyrene on the roof), renewal of the lighting system, insulation of the flat roof $(6 \mathrm{~cm}$ under the concrete), lighting control (occupancy control), sun protection on south windows (inside).

- Thermal renovation "complete": Like thermal renovation "light", plus additional insulation of the outer wall (thermal insulation compound system with 
$20 \mathrm{~cm}$ of polystyrene), renewal of all windows (double glazing, metal frame with sealing), sun protection on east and west windows (inside).

In a second step, these concepts have been extended. The ECA does not propose the integration of a pellet heating or a photovoltaic system. These concepts have been calculated based on literature and a cost comparison carried out by an engineering office. The photovoltaic system has been dimensioned with $5 \mathrm{kWp}$ and an energy production of $800 \mathrm{kWh} /(\mathrm{kWp}$ a). The degradation has been fixed to $5 \% / y e a r$, the yearly costs of operation and maintenance amount to $2,912 € \mathrm{kWp}$ for the module plus the installation. The feed-in tariff is about $0.4301 € / \mathrm{kWh}$ (EEG 2008), for an installation in 2009, with a yearly degression of $8 \%$. This has been subtracted from the yearly energy costs.

For the calculation of profitability, the following assumptions have been made:

expected useful life: 20 years

interest rate: $5 \%$

energy price rise: $3 \% / a$

price rise others: $1.5 \% / \mathrm{a}$

Payback time also depends on those assumptions. It is assessed in a dynamic way. The consequences of a variation of the energy price rise are analysed in the sensitivity analysis. Finally, the decision matrix (Table 3) shows the values for the different criteria for the assessed alternatives.

Phase VIII: relative importance of the criteria

Weights that individual decision-makers attribute to each criterion vary a lot. This is shown by the survey among municipalities in Baden-Württemberg: standard deviation amounts to about $20 \%$ for the question "Which criteria were decisive for the thematic focus of your actions against climate change?" (scale 0-10, cf. "Criteria for the choice of climate protection actions"). In order to generate a representative approach, for the case study, on the level of the single criterion, the average importance out of the survey has been proposed. The applied method was direct point allocation (e.g. Hobbs and Meier 2000; Pöyhönen and Hämäläinen 1998). Table 4 shows the resulting weights on the level of the criteria and Table 5 within one dimension (with the lower and upper bounds calculated from the standard deviation). The vector for the group of financial criteria is $w_{\mathrm{FC}}=$ (initial investment; energy costs; payback time $)=(27.3 ; 37.1 ; 35.7)$. For the inner/outer influence, the vector is described by $w_{\mathrm{IO}}=$ (current support programmes, independence $)=(56.6 ; 43.4)$.

According to the interviewed energy manager, these weights fit well for the analysed case. Finally, the influence of possible deviations on the final result is evaluated in the sensitivity analysis and the representation of the GAIA brain (cf. Fig. 13).

Phase IX: application of the MCDA method

$18(m)$ alternatives $a_{i}$ have been analysed under consideration of seven $(n)$ criteria $c_{i}$. Their values $f_{i}\left(a_{i}\right)$ are known. The analysis has been performed in seven steps 


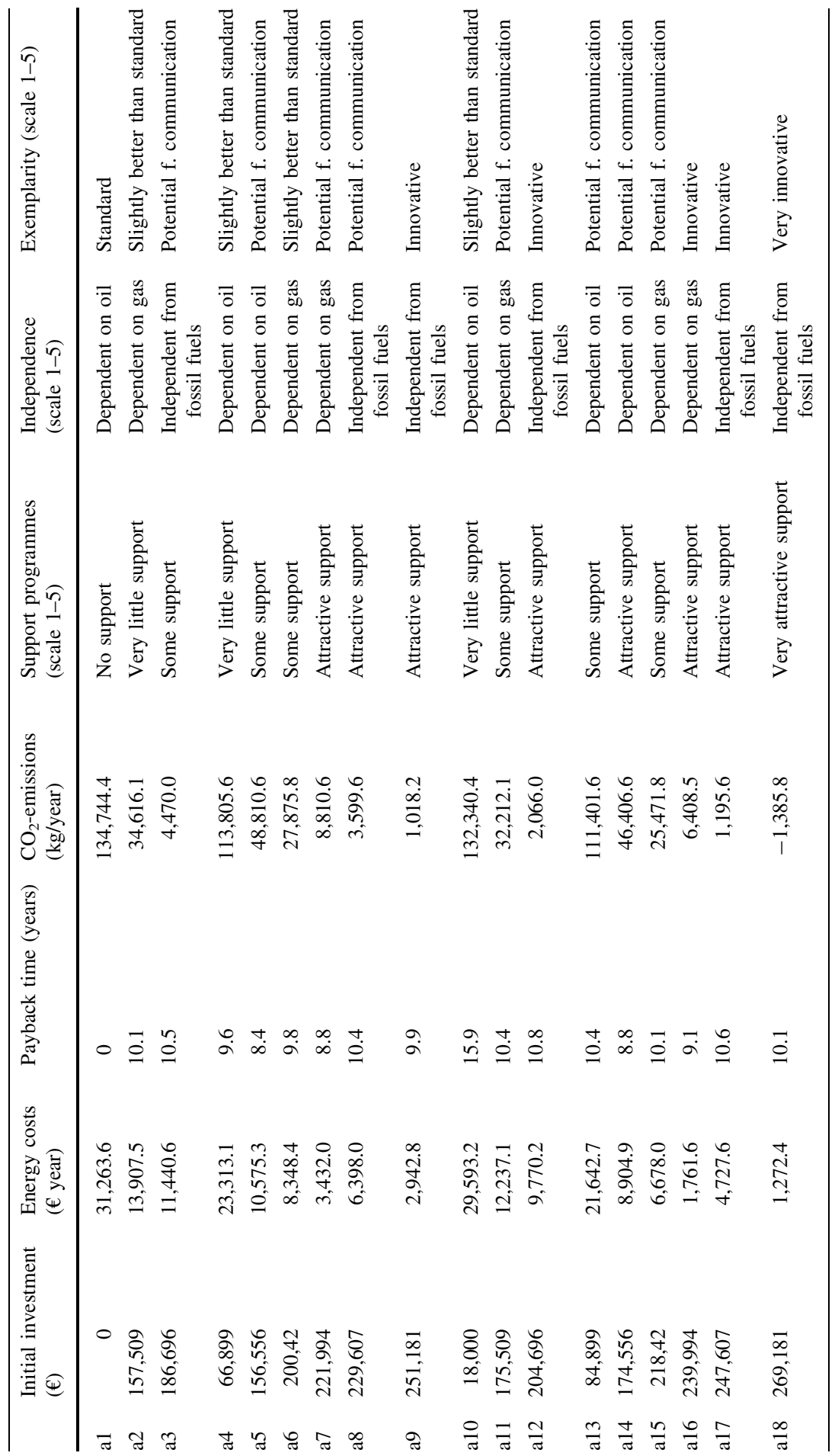


Table 4 Weighting on the level of criteria

\begin{tabular}{lll}
\hline Criterion & Average importance according to survey (scale 0-10) & Weight (in \%) \\
\hline Initial investment & 5.24 & 12.6 \\
Energy costs & 7.12 & 17.1 \\
Payback time & 6.85 & 16.5 \\
$\mathrm{CO}_{2}$-emissions & 6.36 & 15.3 \\
Current support programmes & 6.28 & 15.1 \\
Independence & 4.84 & 11.6 \\
Exemplarity & 4.88 & 11.7 \\
\hline
\end{tabular}

Table 5 Tolerance region for the relative weights of the criteria (in \%)

\begin{tabular}{llll}
\hline Criterion & Lower bound & Weighting in one dimension of criteria & Upper bound \\
\hline Initial investment & 21.8 & 27.3 & 32.7 \\
Energy costs & 29.7 & 37.1 & 44.5 \\
Payback time & 28.5 & 35.7 & 42.8 \\
$\mathrm{CO}_{2}$-emissions & 80 & 100 & 120 \\
Current support programmes & 45.3 & 56.6 & 67.9 \\
Independence & 34.7 & 43.4 & 52.1 \\
Exemplarity & 80 & 100 & 120 \\
Financial benefits & 37.0 & 46.2 & 55.4 \\
Ecological benefits & 12.2 & 15.3 & 18.4 \\
Socio-cultural benefits & 9.4 & 11.7 & 14.1 \\
Inner/outer influence & 21.4 & 26.8 & 32.1 \\
\hline
\end{tabular}

according to PROMETHEE I and II (cf. Brans et al. 1986; Brans and Mareschal 2005).

After the application of PROMETHEE I, an initial partial order is obtained. It is built through set intersection of the primary rankings according to $\phi^{+}$and $\phi^{-}$and results in the partial ranking represented in Fig. 8 (in the so-called diamond, cf. Hayez et al. 2009). This chart represents the positive and negative flows of all alternatives. The negative flow is represented on the left low side and the positive flow is represented on the right low side of the diamond. The horizontal stroked line indicates the global score (net flow score) of the alternative on the so-called thermometer (axis in the middle). The green (grey) part of the thermometer is the positive part (i.e. values between 0 and 1) while the red (black) part represents the negative values (between 0 and -1 ). Crossing lines indicate incomparableness and cluster of close alternatives can be identified in the diamond.

With PROMETHEE II, a complete ranking is achieved. It takes the net balance of all ingoing and outcoming flows (positive and negative flows) and does not allow any incomparability. The complete ranking is represented in Table 6 and Fig. 9. In Fig. 9, the shading of the alternatives (represented as bar in the bar chart) indicates 


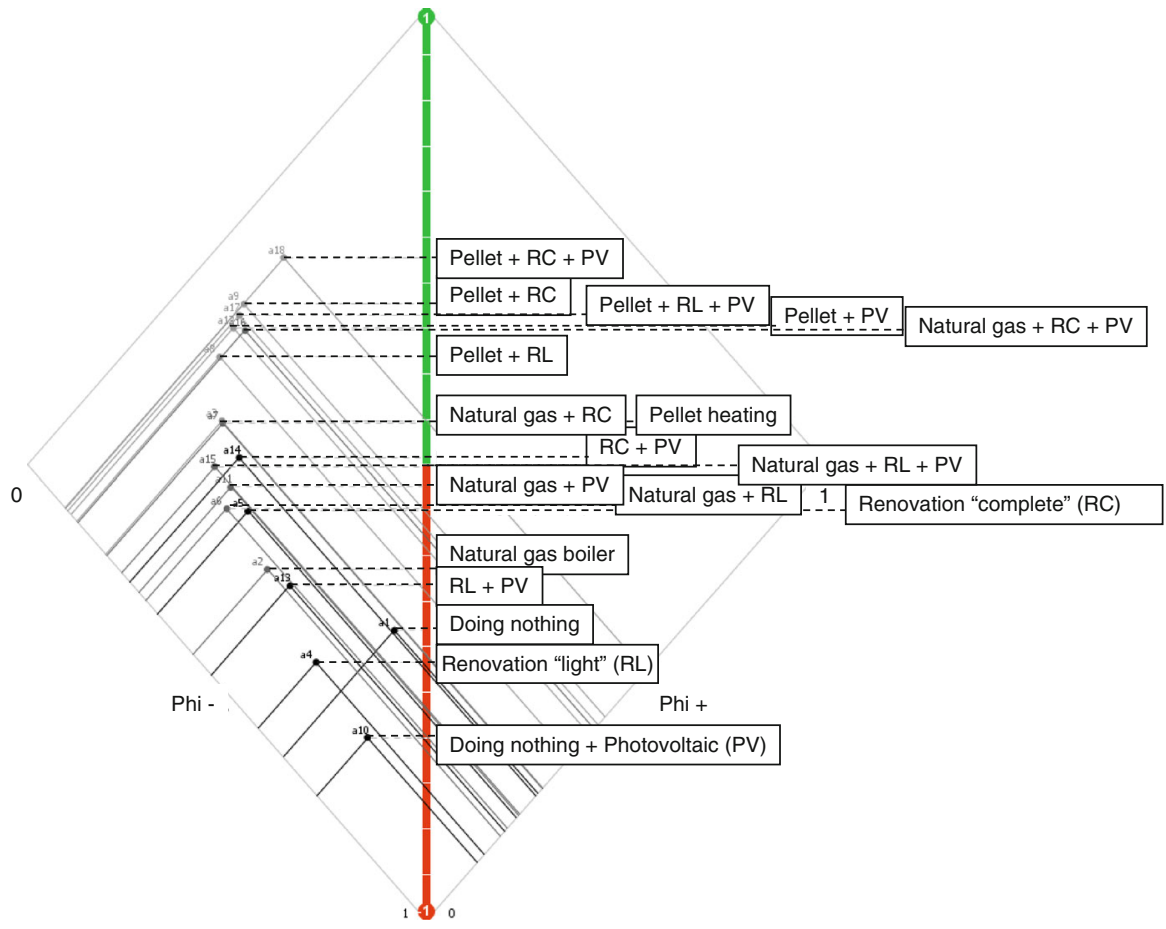

Fig. 8 Diamond (representation with D-Sight, modified) (color figure online)

the energy carrier. Nearly all alternatives that contain the installation of a new pellet heating (grey) are ranked first (cf. Fig. 9). The alternatives with the installation of a new natural gas boiler (shaded dark grey) are mostly situated on the next positions; and finally, those alternatives without exchange of the heating system (black) are ranked behind. Only few exceptions occur, such as a16, the complete renovation with a new natural gas boiler and a photovoltaic system, and a14, the complete renovation with photovoltaics, are placed before the other alternatives with the respective energy carrier. Consequently, the item energy carrier appears to be the most dominant characteristic for the decision-makers. Moreover, they prefer the alternatives with reduction of the consumption (by thermal renovation) to those where simply the heating system is exchanged.

Finally, in the municipality, a new pellet heating is installed and the roof is insulated. Further insulation of the external walls and the replacement of the windows are planned for the coming years. This corresponds to alternative a9, "pellet heating and complete renovation", spread over a few years, ranked on the second place. According to PROMETHEE II, the most expensive solution is ranked first. This is the "ideal" solution for the decision-makers according to the elicited preferences. But the current budget of the municipality does not allow this choice and the second-ranked solution is finally chosen and implemented. Consequently, the PV system cannot be installed immediately. Nevertheless, as communal budgets are redefined regularly and as other financing models, such as financing through a 
Table 6 Position of the alternatives according to PROMETHEE II

Position PROMETHEE II: alternative, short name

1: Pellet + thermal renovation "complete" $(\mathrm{RC})+$ photovoltaic $(\mathrm{PV})$, a18

2: Pellet heating $+\mathrm{RC}$, a9

3: Pellet + thermal renovation light $(\mathrm{RL})+\mathrm{PV}$, a17

4: Pellet + PV, a12

5: Natural gas heating $+\mathrm{RC}+\mathrm{PV}$, a16

6: Pellet heating + RL, a8

7: Pellet heating, a3

8: Natural gas heating $+\mathrm{RC}, \mathrm{a} 7$

9: $\mathrm{RC}+\mathrm{PV}, \mathrm{a} 14$

10: Natural gas heating $+\mathrm{RL}+\mathrm{PV}$, a15

11: Natural gas heating $+\mathrm{PV}, \mathrm{a} 11$

12: Natural gas heating + RL, a6

13: Thermal renovation "complete" (RC), a5

14: Natural gas heating, a2

15: RL + PV, a13

16: Doing nothing, a1

17: Thermal renovation light (RL), a4

18: Photovoltaic (PV), a10

public fund in which the citizens can invest, could be examined, it has been decided at the beginning of the analysis not to introduce a threshold and to carry out a financial feasibility check after the analysis with PROMETHEE.

Phase X: sensitivity analysis and validation

In the last phase of the decision-aiding process, the results are discussed with the decision-makers and their stability is assessed in a sensitivity analysis. One first and very simple step is the variation of the weights of the different criteria. In the software D-Sight, this can be done in real time showing the weights and the resulting ranking simultaneously.

\section{Profiles of decision-makers}

The weighting has been accomplished based on average values from the quantitative survey in Baden-Württemberg (cf. Markl-Hummel et al. 2010; Markl-Hummel 2012). It was described by the vector $w_{\mathrm{ZD}}=$ (financial benefits, ecological benefits, socio-cultural benefits, inner outer drivers $)=(46.2 ; 15.3 ; 11.7 ; 26.8)$. For sensitivity analysis, "extreme" profiles of decision-makers who respectively highlight one single objective more than the others are defined and compared. This can be an environmental activist emphasizing ecological criteria, a treasurer concentrating on financial aspects, the headmaster of the school highlighting social issues or a mayor for whom especially its personal image is important. For these 


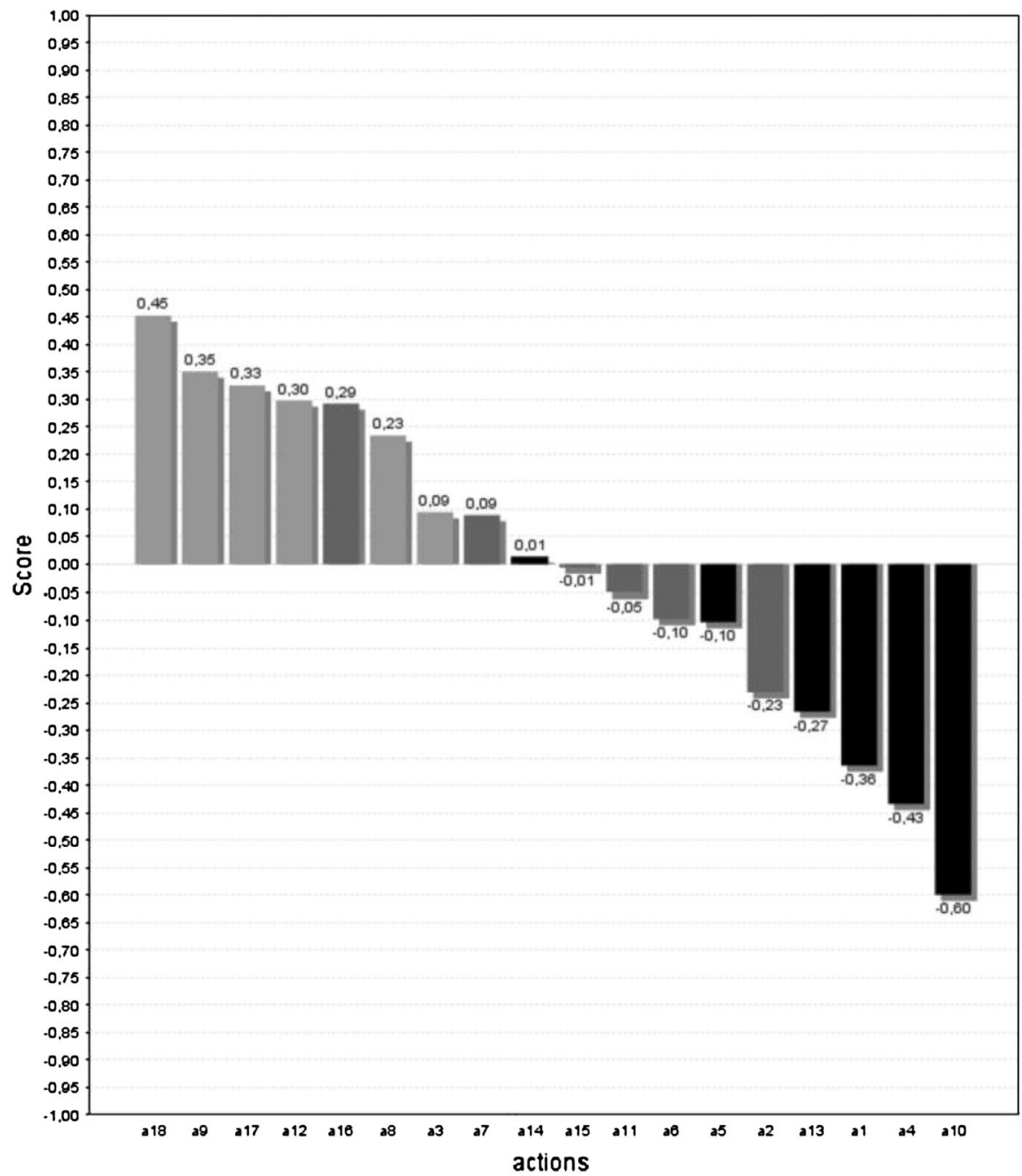

Fig. 9 PROMETHEE II, ranking of the net flows (representation with D-Sight, grey pellets, dark grey gas, black oil)

extreme cases, $60 \%$ are assigned to the main objective and the others are decreased accordingly. The resulting scenarios are:

Scenario F (financial benefits are most important): $w_{\mathrm{ZF}}=(60 ; 11 ; 9 ; 20)$.

Scenario E (ecological benefits are most important): $w_{\mathrm{ZE}}=(22 ; 60 ; 5 ; 13)$.

Scenario S (socio-cultural benefits are most important): $w_{\mathrm{ZS}}=(21 ; 7 ; 60 ; 12)$.

Scenario I (inner/outer drivers are most important): $w_{\mathrm{ZI}}=(25 ; 8 ; 7 ; 60)$.

This leads to changes in the ranking as shown in Fig. 10. It reveals that the two first alternatives are stable. The largest gaps appear in the ecological scenario E, when the decision-maker assigns $60 \%$ to $\mathrm{CO}_{2}$-emissions. In this case, the alternative a14 (complete refurbishment with PV) will "slip four notches" 


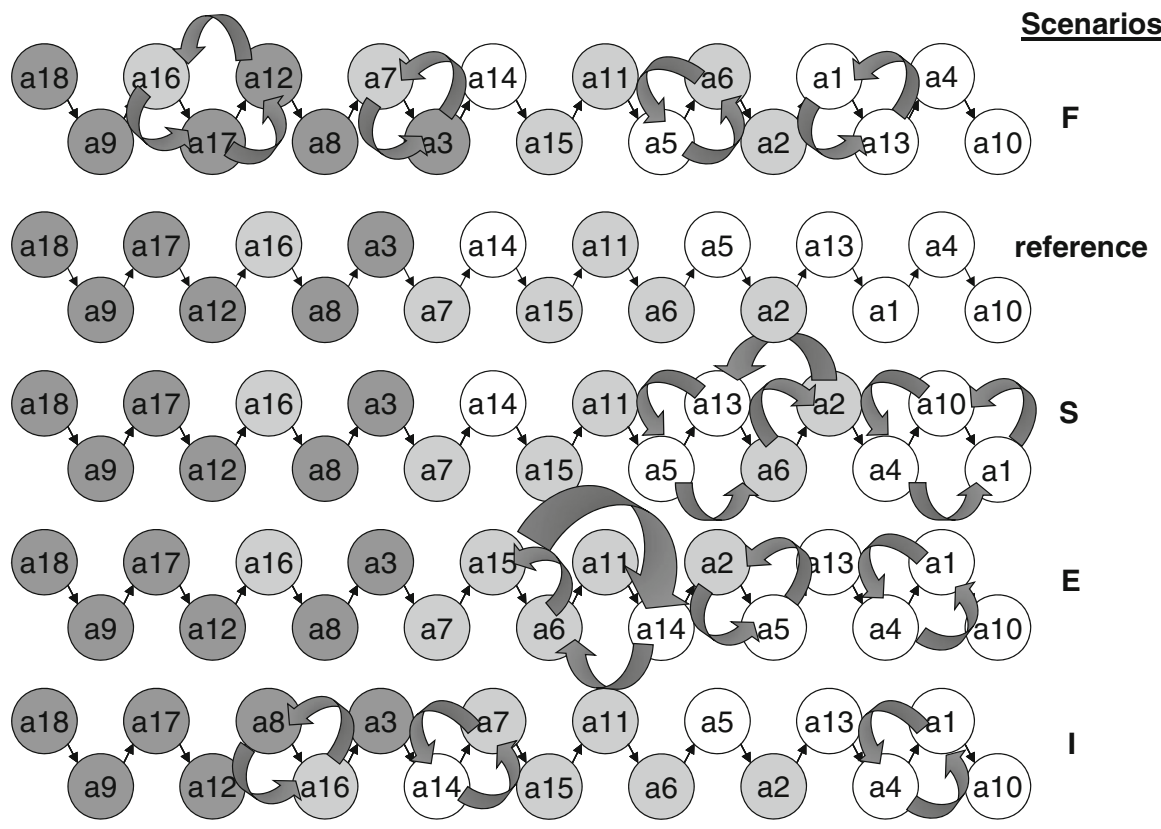

Fig. 10 Changes in the ranking according to extreme profiles of the decision-maker ( $F$ financial benefits are most important, $S$ social, $E$ ecological, $I$ inner/outer drivers)

compared to the average scenario, but the first eight alternatives will remain unchanged. In the social-cultural scenario S, the first 11 alternatives are stable.

\section{GAIA}

Another sensitivity analysis is carried out with GAIA (Geometrical Analysis for Interactive Assistance). The visual representation allows analysing the dependence between the criteria and the alternatives as well as the stability of the problem (Brans and Mareschal 2002). It can be shown to the decision-makers in order to discuss the results together. In D-Sight, the GAIA plane, the decision stick (the weight vector, cf. Brans and Mareschal 2002, p. 104), the alternatives and the criteria are represented, cf. Fig. 11. In Fig. 12, only criteria are represented in order to improve visibility. One can see, for example, that the criteria "support programmes" and "exemplarity" are very close to each other and are oriented in the same direction while "initial investment" and "energy costs" are conflicting (their vectors are oriented in opposed directions). The alternatives build clusters according to the energy carrier. This is a sort of meta criterion to characterize the different alternatives.

The longer the axis of a criterion is, the more discriminating it is (Brans and Mareschal 2002). For the case study, the criteria " $\mathrm{CO}_{2}$-emissions", "support programmes", "exemplarity" and "independence" are concerned in particular.

With the GAIA brain (framed area on the top of the decision stick), a sensitivity analysis of the weighting can be carried out. It shows the variations of the decision stick (weighting vector on the decision axis which shows the direction of the 


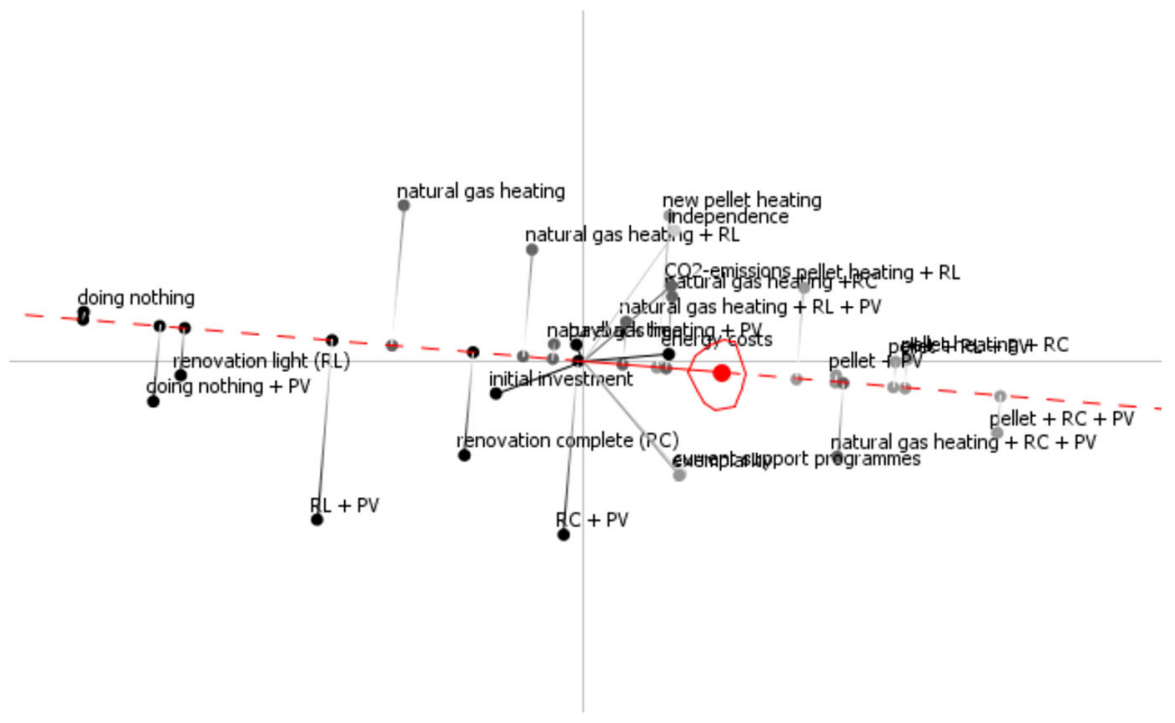

Fig. 11 Representation of the GAIA plane in D-Sight (with GAIA brain and stick projections, $\delta=87.6 \%$ )

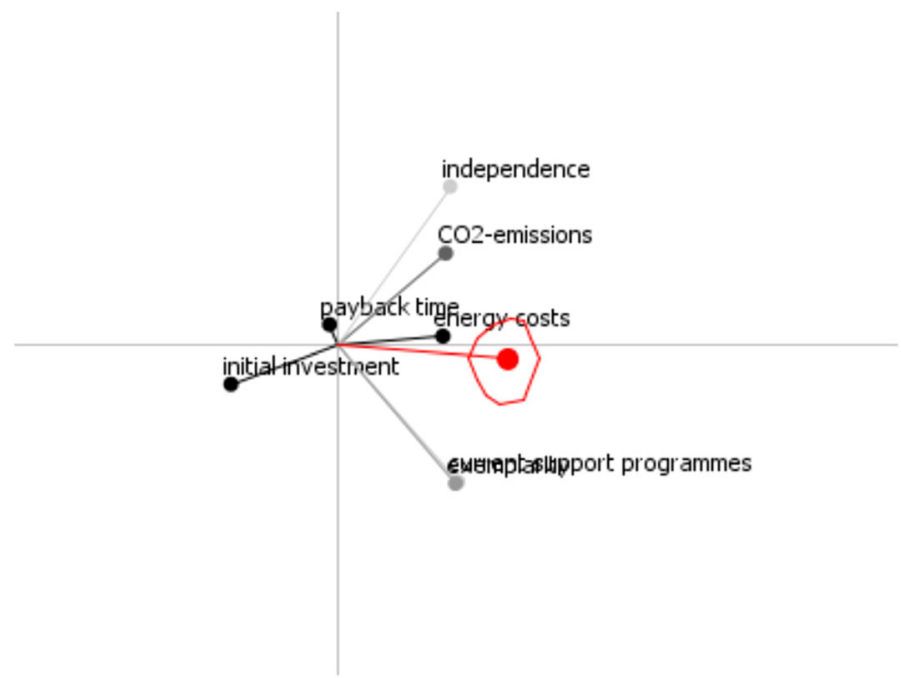

Fig. 12 Representation of the criteria in the GAIA plane in D-Sight (with GAIA brain, $\delta=87,6 \%$ )

PROMETHEE II ranking) in the defined tolerance region for deviations of the weight. For the case study, the tolerance region has been based on the results of the survey among municipalities in Baden-Württemberg (cf. Markl-Hummel et al. 2010; Markl-Hummel 2012; cf. Table 5). The GAIA brain shows the resulting tolerance region for all probable weightings (cf. Table 5). The delta value which measures the quality of the GAIA representation (the percentage of information 
contained in the two-dimensional representation) is large enough (higher than $70 \%$ ) to conclude that the decision problem is stable.

\section{Stability intervals}

Another way of examining the stability of a problem and the impact of changing weights is the analysis of stability intervals, cf. Tables 7 and 8 . The stability intervals indicate the range in which the weight of a criterion can be changed without affecting the ranking. In the two tables, the first column contains the criteria. The second, third and fourth columns equate the lower bound, the current value and the upper bound of the criterion's weight. A stability level of $n$ means that changes in the ranking of the $n$ first alternatives are considered. The bigger the level is, the smaller the intervals are. In the case study, the stability level is very high. For changing the first ranked alternative (stability level of 1), the initial investment has to be weighted with $>34.6 \%$ or the payback time with $>53.6 \%$. The second placed alternative will already be changed with a weight of the initial investment of $>24.3 \%$ or energy costs $<6.9 \%$. This indicates a "simple" problem (Brans and Mareschal 2002, p. 90). The most sensitive criterion, which leads to changes in the ranking of the first ranked alternative when its weight is changed the less (cf. Geldermann 2005, p. 138), is the criterion "initial investment".

Table 7 Stability level 1

\begin{tabular}{lllc}
\hline Criterion & Min weight $(\%)$ & Value $(\%)$ & Max weight $(\%)$ \\
\hline Initial investment & 0.0 & 12.6 & 34.5 \\
Energy costs & 0.0 & 17.1 & 100.0 \\
Payback time & 0.0 & 16.5 & 53.4 \\
$\mathrm{CO}_{2}$-emissions & 0.0 & 15.3 & 100.0 \\
Current support programmes & 0.0 & 15.1 & 100.0 \\
Independence & 0.0 & 11.6 & 100.0 \\
Exemplarity & 0.0 & 11.7 & 100.0 \\
\hline
\end{tabular}

Table 8 Stability level 2

\begin{tabular}{lllc}
\hline Criterion & Min weight $(\%)$ & Value $(\%)$ & Max weight $(\%)$ \\
\hline Initial investment & 0.0 & 12.6 & 24.3 \\
Energy costs & 6.9 & 17.1 & 54.5 \\
Payback time & 0.0 & 16.5 & 51.0 \\
$\mathrm{CO}_{2}$-emissions & 0.0 & 15.3 & 100.0 \\
Current support programmes & 0.0 & 15.1 & 100.0 \\
Independence & 3.6 & 11.6 & 100.0 \\
Exemplarity & 0.0 & 11.7 & 100.0 \\
\hline
\end{tabular}




\section{Energy price rise}

Further sensitivity analysis has been carried out on the energy price rise. Figure 13 illustrates the changes in the ranking due to the changed payback time depending on the energy price rise. Only minor changes can be detected for a constant energy price. If energy becomes more expensive, the ranking stays stable.

Other criteria could also be varied, such as new support programmes that appear or technological bonds that diminish the initial investment. But the timeframe of the analysed decision is rather short (maximal one year before the start of the first works). So, it can be assumed that no major changes will occur. Additional sensitivity analysis could be carried out on the other hypotheses that have been taken such as the chosen preference functions, thresholds, etc. But since the analysed problem is stable and as the purpose of the case study is to improve transparency and comprehensibility for the decision-makers, this is not presented in this article. For systematic sensitivity analyses with PROMETHEE, Geldermann et al. (2003), Treitz (2009) or (Bertsch 2008) can be referred.

A final discussion with the municipality revealed that the chosen hypotheses fit well with reality. The evaluation of the criteria and alternatives was helpful and structured well the decision process. Just the representation in the diamond was judged as too complicated.

\section{Energy price rise}

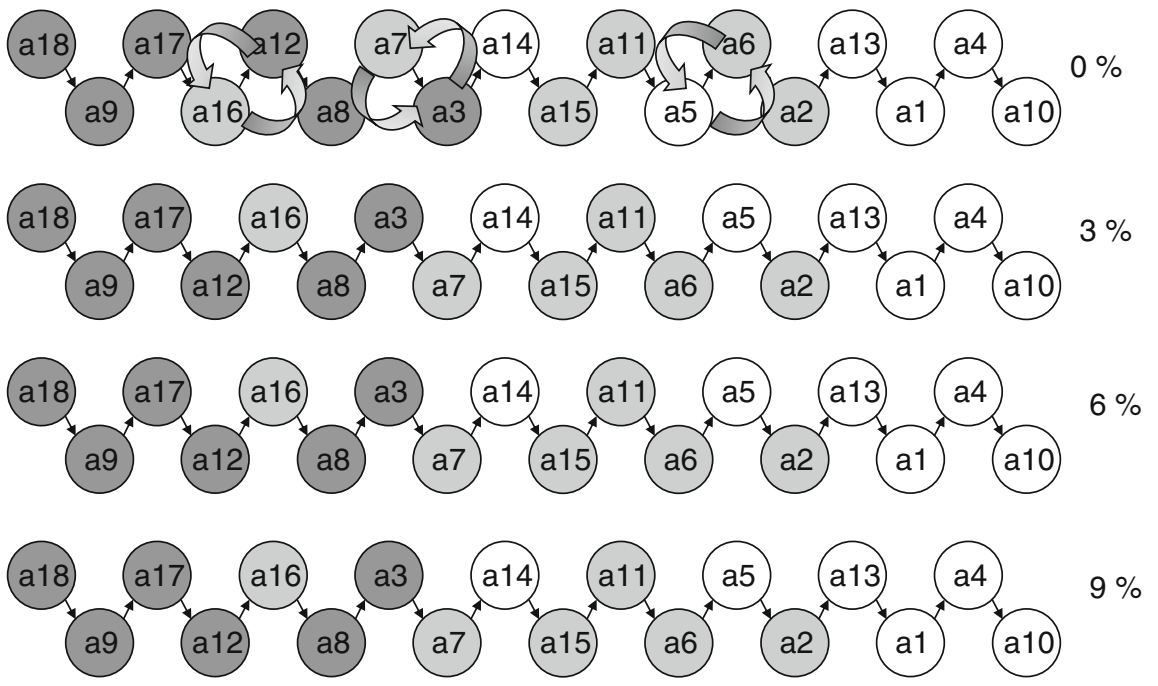

Fig. 13 Changes in the ranking with different energy price rise assumptions (compared to $3 \%$ ) 


\section{Conclusion and outlook}

The presented work allows some conclusions on decisions on local climate protection in general and the description of the context in German municipalities in particular. Local authorities can be considered as key actors for climate protection. They are next to the citizens and have a broad range of actions. But the number of climate protection strategies and their implementation can still be improved. Currently, not all ecologically worthwhile and economically viable solutions are implemented, mainly due to a lack of motivation and information in politics and administration. Decision aiding for the local decision-makers can be one way to overcome these barriers. The decision process becomes more transparent, all relevant persons can be integrated and information is shared. Thereby, analysis reveals a very large field of action with potential need for decision aiding in local climate protection. It varies depending on the concerned decision-makers (from partly purely political motivated decisions taken by the mayor to very practical operational consideration of members of administration), on the kind of decision (sorting, ranking, choice) and on the local context (e.g. existing know-how and available budget). In literature, mainly decisions on national level or very specific local decision problems like building refurbishment have been tackled. The approach for decision aiding on local level addressing climate protection strategies and its different stages has some particular characteristics: a specific mix of interests can be observed because the local political decision-makers are more closely confronted to the will of their electors than national representatives. Moreover, in German municipalities, executive and legislative powers are interacting very strongly because the mayor is simultaneously the head of administration and political representative. Overall, political decisions also contain emotional and tactical reflections that cannot always be represented in a rational way. Consequently, personal interaction between the decision-makers and the analyst plays a very important role throughout the whole process. Local conditions and personal preferences have to be reflected and are partly rather subjective while on a more generalised level, more objective criteria can be taken into account and optimisation techniques can be applied. The survey among municipalities in BadenWürttemberg has shown the broad range of criteria that are considered for the choice of actions for climate protection. These have been concentrated in an "ideal criteria tree" (cf. Fig. 5) which serves as basic value system to be customised for the local context. Furthermore, the work allowed the identification of different decision moments during the elaboration of a climate protection strategy and its implementation: (1) strategical decision; (2) assessment of possible actions for the municipality, decision on integration of actions; (3) precision of the action plan and (4) ranking of alternatives for concrete actions. All decision moments necessitate different decision-aiding techniques and different approaches. For instance, the outranking method PROMETHEE can be applied for the choice between different alternatives for the implementation of one action. This has been tested on a case study. It illustrates that PROMETHEE creates high transparency by representing the individual preferences of the decision-makers and comparing each alternative to all others. The possibilities of visualisation are helpful for sensitivity 
analysis and the understanding of the interactions between criteria and alternatives. Sensitivity analysis turned out that a "simple" problem has been treated and the final recommendations represent well the decision-makers preferences. The application of the tools Energy Concept Advisor and D-Sight allowed reducing costs and time of the study, well adapted to the limited budget of the municipality. The case study also showed how important it is to keep a process oriented approach in order to accompany the decision-makers effectively through the whole decision process and to explain each step. This is one of the advantages of outranking methods in general which highlight the importance of a dialogue (cf. Oberti 2004). The standardised phases in the decision-aiding process (cf. Fig. 2) improve the bindingness of the exchange. Nevertheless, it was confirmed that in practice, the mayor as the head of administration is the most relevant decision-maker (especially in small municipalities). Her preferences are pivotal even if other persons are also concerned and a group decision is moderated by an external analyst. To complement the analysis, other multicriteria decision-aiding methods could also have been applied in the case study but we did not want to confuse the decision-makers. If the study would have to be redone, more contact with the different stakeholders would have been desirable. Moreover, it would have been interesting to include other alternatives, e.g. the simultaneous refurbishment of other public buildings in order to get more competing options that would not all have been comparable. In that case, the number of alternatives would have become very fast very high and Portfolio Decision Analysis could have been applied in order to select a subset. In addition, in further research, a detailed "roadmap for decision aiding" in every decision moment during the preparation and implementation of a local climate protection concept could be established. The proposition of a standard set of measures is not considered as meaningful, because local conditions vary too strongly from one municipality to another.

\section{References}

Asadi E, da Silva MG, Antunes CH, Dias L (2012) Multi-objective optimization for building retrofit strategies: a model and an application. Energy Build 44:81-87

Bertsch V (2008) Uncertainty handling in multi-attribute decision support for industrial risk management. $\mathrm{PhD}$ work, Universitätsverlag Karlsruhe

BMU-Federal Ministry for the Environment, Nature Conservation and Nuclear Safety, "The climate initiative". http://www.bmu-klimaschutzinitiative.de. Last retrieved on 23.04.2012 (2010)

Bombenger PH, Waaub JP (2010) The integrated rural planning system, an evaluative and participative method of decision-making support to build a sustainable urban development in the Ballons des Vosges Natural Regional Park. In: Proceedings of IT-GO

Brans J-P, Mareschal B (2002) PROMETHEE-GAIA-une méthodologie d'aide à la décision en présence de critères multiples, SMA, Bruxelles : Editions de l'université de Bruxelles, Ellipses

Brans J-P, Mareschal B (2005) PROMETHEE methods. In: Figueira J, Greco S, Ehrgott M (eds) Multiple criteria decision analysis: state of the art surveys. Springer, New York, pp 163-195

Brans J-P, Vincke P, Mareschal B (1986) How to select and how to rank projects: the PROMETHEE method. Eur J Oper Res 24:228-238

Bulkeley H, Kern K (2004) Local climate change policy in the United Kingdom and Germany. Discussion Paper SP IV 2004-103, Wissenschaftszentrum Berlin für Sozialforschung WZB 
Behzadian M, Hosseini-Motlagh S-M, Ignatius J, Goh M, Sepehri MM (2011) PROMETHEE group decision support system and the house of quality. Springer, Berlin

Ceccato L, Giannini V, Giupponni C (2009) A participatory approach for assessing alternative climate change adaptation responses to cope with flooding risk in the Upper Brahmaputra and Danube River Basins, University Ca' Foscari of Venice, Dept. of Economics Research Paper Series No. 18_09

Diakaki C, Grigoroudis E, Kabelis N, Kololotsa D, Kalaitzakis K (2010) A multi-objective decision model for the improvement of energy efficiency in buildings. Energ Effic 35:5483-5496

Diakoulaki D, Antunes CH, Martins AG (2005) MCDA and energy planning, In: Figueira J, Greco S, Ehrgott M (eds) Multiple criteria decision analysis: state of the art surveys, Springer, New York, pp 859-897

Dinca C, Badea A, Rousseaux P, Apostol T (2007) A multi-criteria approach to evaluate the natural gas energy systems. Energy Policy 35(11):5754-5765

EEG, Act on granting priority to renewable energy sources (Renewable Energy Sources Act, EEG), Gesetz für den Vorrang Erneuerbarer Energien (Erneuerbare-Energien-Gesetz, EEG), Date of issue: 25 October 2008. http://www.erneuerbare-energien.de. Last retrieved on 23/04/2012

Erhorn H, Boer de J, Kluttig H (2002) Der Energy Concept Adviser-Ein neues Planungswerkzeug für Bauverwaltungen aus dem IEAECBCSAnnex 36

Fischer A, Kallen C (eds) (1997) Klimaschutz in Kommunen. Leitfaden zur Erarbeitung und Umsetzung kommunaler Klimakonzepte, Verlag Deutsches Institut für Urbanistik, Berlin

Figueira J, Greco S, Ehrgott M (eds) (2005) Multiple criteria decision analysis: state of the art surveys, Springer, New York

Geldermann J (1999) Entwicklung eines multikriteriellen Entscheidungsunterstützungssystems zur integrierten Technikbewertung. Dissertation, Institut für Industriebetriebslehre und Industrielle Produktion (IIP) /Deutsch-Französisches Institut für Umweltforschung (DFIU) Universität Karlsruhe (TH), Düsseldorf: VDI

Geldermann J (2005) Mehrzielentscheidungen in der industriellen Produktion, Habilitation, Universität Karlsruhe (TH), Fakultät für Wirtschaftswissenschaften, Universitätsverlag Karlsruhe

Geldermann J, Zhang K, Rentz O (2003) Sensitivitätsanalysen für das Outranking-Verfahren PROMETHEE. In: Habenicht W, Scheubrein B, Scheubrein R (eds) Multi-Criteria- und Fuzzy-Systeme in Theorie und Praxis Lösungsansätze für Entscheidungsprobleme mit komplexen Zielsystemen, Gabler Edition Wissenschaft, Deutscher Universitäts-Verlag, Wiesbaden, pp 127-151

Grafakos S, Zevgolis D (2008) ECPI Decision Support Tool: energy and climate policy interactions: weighting of criteria in ECPI Decision Support Tool, National Technical University of Athens, Greece

Grafakos S, Zevgolis D, Flamos A, Oikonomou V (2009) Integrating environmental, sociopolitical, economic and technological dimensions for the assessment of climate policy instruments, paper in online conference "Climate 2009"

Greening LA, Bernow S (2004) Design of coordinated energy and environmental policies. Use of multicriteria decision making. Energy Policy 32((6):721-735

Gregory R, Arvai J, McDaniels T (2001) Value-focused thinking for environmental risk consultations. Res Soc Probl Public Policy 9:249-273

Hayez Q, Mareschal B, De Smet Y (2009) New GAIA visualization methods. In: Proceedings of the 13th international conference on information visualization 2009, Barcelona IEEE Computer Society, pp 247-251 (2009)

Hennicke P, Jochem E, Prose F (eds) (1997) Interdisziplinäre Analyse der Umsetzungschancen einer Energiespar- und Klimaschutzpolitik, Forschungsbericht, Karlsruhe, Kiel, Wuppertal

Hobbs BF, Meier P (2000) Energy decisions and the environment. A guide to the use of multicriteria methods, Kluwer, Dordrecht (2000)

IPCC (2007) Fourth assessment report "Climate Change 2007”, four volumes. http://www.ipcc.ch. Last retrieved on 30/08/2010, (2007)

Keeney RL (1992) Value-focused thinking: a path to creative decisionmaking. Harvard University Press, Cambridge, MA

Konidari P, Mavrakis D (2006) Multi-criteria evaluation of climate policy interactions. J Multi-Criteria Decis Anal 14(1-3):35-53

Laborgne P, Huber A (2008) PEREBAT: Les Politiques Energétiques développées par les régions dans le cadre du bâti - Les politiques à l'échelle de la commune: Königsfeld, Heidelberg et Stuttgart, PEREBAT 
Macharis C, Brans J-B, Mareschal B (1998) The GDSS PROMETHEE procedure. J Decis Syst 7:283307

Markl L, Avci N (2009) Kommunen als Akteure im Klimaschutz. In: Cail S, Möst D, Fichtner W, Percebois J (eds) Umweltpolitische Ziele der EU: Deutsch-französische Beiträge zur Zielerreichung-Concepts franco-allemands pour atteindre les objectifs environnementaux de IUE. KIT Scientific Publishing, Karlsruhe

Markl-Hummel L (2012) Multikriterielle Entscheidungsunterstützung für kommunale Klimaschutzmaßnahmen. Dissertation zur Erlangung des wissenschaftlichen Doktorgrades der Wirtschaftswissenschaftlichen Fakultät der Universität Göttingen, Cuvilier Verlag Göttingen

Markl-Hummel L, Laborgne P, Pfenning U (2010) Local authorities as key actors for climate protection in Germany and in France. In: EURA conference understanding city dynamics, 24.09.-26.09.2010 in Darmstadt/Germany, paper presented in Track 4: Sustainability: Local meanings and strategies

Neves AR, Leal V (2010) Energy sustainability indicators for local energy planning: review of current practices and derivation of a new framework. Renew Sustain Energy Rev 14:2723-2735

Neves LP, Martins AG, Antunes CH, Dias LC (2008) A multi-criteria decision approach to sorting actions for promoting energy efficiency. Energy Policy 36:2351-2363

Oberschmidt J (2010) Multikriterielle Bewertung von Technologien zur Bereitstellung von Strom und Wärme. Dissertation zur Erlangung des wissenschaftlichen Doktorgrades der Wirtschaftswissenschaftlichen Fakultät der Universität Göttingen, Fraunhofer Verlag

Oberti P (2004) Décision publique et recherche procédurale: illustration d'une démarche multicritère àà la localisation participative dun parc éolien en région corse. Journées de 1'Association Française de Science Economique, "Economie : aide àà la décision publique", Université de Rennes 1

Pohekar SD, Ramachandran M (2004) Application of multi-criteria decision making to sustainable energy planning-a review. Renew Sustain Energy Rev 8(4):365-381

Pöyhönen M, Hämäläinen R (1998) Notes on the weighting biases in value trees. J Behav Decis Mak 11(2):139-150

Prose F, Hübner G, Kupfer D (1993) Zur Organisation des Klimaschutzes auf der kommunalen Ebene, Forschungsbericht / 2. Zwischenbericht, Juni 1993, Institut f. Psychologie, Christian- AlbrechtsUniversität, Kiel

Rencher AC (2002) Methods of multivariate analysis, second edn. Wiley, New York

Roy B (1985) Méthodologie multicritère d'aide à la décision, Economica, Paris

Roy B (2005) Paradigms and challenges. In: Figueira J, Greco S, Ehrgott M (eds) Multiple criteria decision analysis: state of the art survey. Springers International Series

Roy B, Bouyssou D (1993) Aide multicritère à la décision, Economica, Paris

Salo A, Keisler J, Morton A (eds) Advances in portfolio decision analysis: improved methods for resource allocation. Springer, New York

Simon HA (1976) Administrative behavior: a study of decision-making-processes in administrative organizations, 3rd edn. Free Press, New York

Solarsatzung Marburg (2010) Satzung der Universitätsstadt Marburg zur verbindlichen Nutzung der Solarenergie in Gebäuden (Solarsatzung). http://www.marburg.de. Last retrieved on 23.04.2012

Treitz M (2006) Production process design using multi-criteria analysis. Dissertation, Universitätsverlag Karlsruhe

Tsoutsos T, Drandaki M, Frantzeskaki N, Iosifidis E, Kiosses I (2009) Sustainable energy planning by using multi-criteria analysis application in the island of Crete. Energy Policy 37((5):1587-1600

Wang J, Jing Y-Y, Zhang C-F, Zhao J-H (2009) Review on multi-criteria decision analysis aid in sustainable energy decision-making. Renew Sustain Energy Rev 13:2263-2278

Weimer-Jehle W, Hampel J, Pfenning U (2001) Kommunaler Klimaschutz in Baden-Württemberg: Ergebnisse einer Umfrage bei Gemeinden, Arbeitsbericht der Akademie für Technikfolgenabschätzung in Baden-Württemberg Nr. 187

Weissfloch U, Geldermann J (2012) Dealing with conflicting targets by using group decision making within PROMETHEE. In: Klatte D et al (eds) Operations research proceedings 2011. Springer, Berlin pp 115-120

Zhou P, Ang BW, Poh KL (2006) Decision analysis in energy and environmental modelling: an update. Energy 31:2604-2622 